\title{
Investigation of the Transient Nature of Thunderstorm Winds from Europe, the United States, and Australia Using a New Method for Detection of Changepoints in Wind Speed Records
}

\author{
DJORDJE ROMANIC \\ Wind Engineering, Energy and Environment Research Institute, Western University, London, Ontario, Canada, and \\ Department of Atmospheric and Oceanic Sciences, McGill University, Montreal, Quebec, Canada, and Department of Civil, \\ Chemical and Environmental Engineering (DICCA), Polytechnic School, University of Genoa, Genoa, Italy \\ Junayed Chowdhury, Jubayer ChOwdhury, ANd Horia Hangan \\ Wind Engineering, Energy and Environment Research Institute, Western University, London, Ontario, Canada
}

(Manuscript received 23 September 2019, in final form 27 June 2020)

\begin{abstract}
This paper investigates the transient characteristics in 41 velocity records of 19 thunderstorm events from around the world -9 from Europe, 9 from the United States, and 1 from Australia. The transient features of thunderstorm winds were examined by introducing an objective method for the detection of changepoints in the time series. The methodology divides velocity records into segments characterized by different statistical properties. The segmentation is based on the following properties of the isolated segments: mean (M) and the standard deviation (SD). This study demonstrated that the maximum velocity during the thunderstorm peak in the events from Europe is typically 2-4 times larger than the mean wind speed before the thunderstorm. The duration of the thunderstorm velocity peak was 2-5 min in approximately $60 \%$ of the analyzed records using the M statistic and 5-10 min when analyzed using the SD statistic. Therefore, the velocity fluctuations caused by thunderstorm winds last longer than the abrupt changes in the mean wind field. Similarly, the rampup time was longer when the records were analyzed using the SD statistic. The segmentation methodology was tested for different duration of velocity records and using data with different sampling frequencies. The performances of the introduced method were compared against the results of two other segmentation procedures proposed in the literature. One of the practical applications of this method is the physical separation between the thunderstorm and nonthunderstorm components of a wind event.
\end{abstract}

\section{SIGNIFICANCE STATEMENT}

Thunderstorm outflow winds are short-lived phenomena produced by cold downdrafts that originate in thunderstorm clouds. This study analyzes the transient nature of thunderstorm winds from Europe, the United States, and Australia using a segmentation method applied to anemometer velocity records. This segmentation method identifies abrupt changes of mean wind speed and wind fluctuations in the velocity data. This research provides the means of isolating different segments within the thunderstorm wind records in an objective way that is based on rigorous mathematical principles. The proposed method can automatically distinguish thunderstorm from nonthunderstorm winds. The peak velocities in thunderstorm outflows are 2-4 times the mean wind speed before the thunderstorm. The most intense episodes of thunderstorm winds usually last $2-5 \mathrm{~min}$.

\section{Introduction}

Thunderstorms are severe weather phenomena that produce strong winds close to the surface, as well as potentially large amounts of precipitation, hail, and

Corresponding author: Djordje Romanic, dromanic@uwo.ca lightning. Analyzing catastrophic events caused by thunderstorms from 1948 to 1998 across the United States, Changnon (2001) noticed that, while the major damage caused by some thunderstorms was due to either hail, lightning, tornadoes or heavy rain, all of the investigated events were also characterized by strong surface winds. The downdraft-associated winds from thunderstorms are 
usually classified into downbursts, gust fronts, rear-flank downdrafts (RFD), and forward-flank downdrafts (FFD). Conceptual models of these downdrafts, their origin, and dynamics can be found in Goff (1976), Lemon and Doswell (1979), Wakimoto (1982), Fujita (1985), Markowski (2002), and Shabbott and Markowski (2006), among others.

The transient nature of thunderstorm winds is best depicted by comparing their velocity records against a steady atmospheric boundary layer (ABL) wind (Fig. 1). While a time-independent mean is sufficient at describing the mean ABL flow (Fig. 1a), the same approach does not apply in the example of thunderstorm winds (Fig. 1b). That is, the classical Reynolds decomposition in which the instantaneous wind speed is decomposed into the time-independent mean and time-dependent, but stationary, residual fluctuations does not hold for thunderstorm winds (Fig. 1b).

Fujita (1985) proposed an algorithm for microburst detection based on the 1-min maximum wind speed $\hat{U}_{1 \text { min }}$, as well as the prepeak mean wind speed $\bar{U}_{-}$and postpeak mean wind speed $\bar{U}_{+}$. The last two $\left(\bar{U}_{-}, \bar{U}_{+}\right)$ are calculated from seven 1-min segments with the first minute before and after the peak excluded from the analysis. The following conditions have to be satisfied simultaneously in order for an event to be classified as microburst: 1) $\hat{U}_{1 \min }>10 \mathrm{~m} \mathrm{~s}^{-1}$, 2) $\hat{U}_{1 \min }>\bar{U}_{+}+5$ and $\left.\hat{U}_{1 \min }>\bar{U}_{-}+5,3\right) \hat{U}_{1 \min }>1.25 \bar{U}_{+}$and $\hat{U}_{1 \min }>1.25 \bar{U}_{-}$, and last 4) $\bar{U}_{+} \leq 1.5 \bar{U}_{-}$. Microbursts are downbursts with the horizontal scale of the outflow below $4 \mathrm{~km}$. Fujita (1985) applied this algorithm to over 5 million 1-min wind records and extracted 579 microbursts from Northern Illinois Meteorological Research on Downburst (NIMROD) and Joint Airport Weather Studies (JAWS) field campaigns combined.

Lombardo et al. (2009) put forward a methodology that separates thunderstorm from nonthunderstorm winds in the Automated Surface Observing System (ASOS) hourly data. The ASOS network of automated weather stations covers most of the continental United States (NCEI 1998; Romanic et al. 2018; Lombardo and Zickar 2019). Due to the coarse time resolution of ASOS data, only the hourly peak values of thunderstorm winds and their duration were obtained and analyzed. Since the method was applied to a large set of data, the research was focused on the underlying statistical distribution of extremes, and the specific time series were not investigated in detail. De Gaetano et al. (2014) implemented an automated procedure for the extraction of three classes of winds from anemometer records: 1) stationary and Gaussian, 2) nonstationary and non-Gaussian, and 3) stationary and non-Gaussian winds. The separation methodology of De Gaetano et al. (2014) was implemented through a sequential algorithm that uses 10-min and 1-h
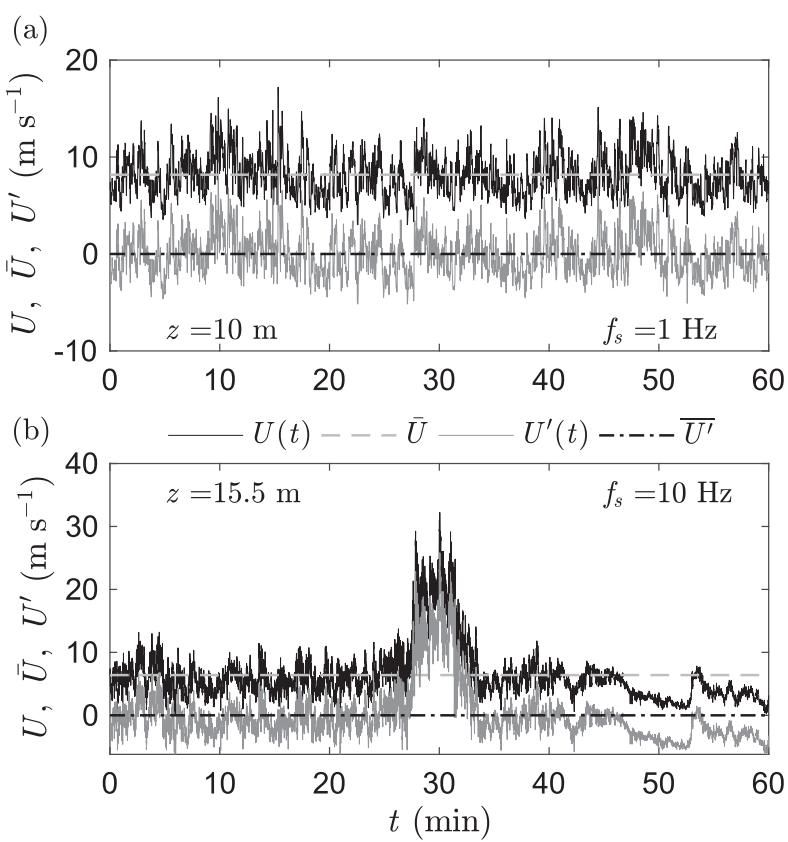

FIG. 1. Hour-long wind speed records (black line) of (a) ABL wind measured in Salt Lake Valley, UT, (Lareau et al. 2013) and (b) thunderstorm wind measured in La Spezia, Italy (Solari et al. 2012). The mean $\bar{U}$ and fluctuations $U^{\prime}(t)$ are obtained using the standard Reynolds decomposition: $U(t)=\bar{U}+U^{\prime}(t)$. Anemometer heights $z$ and sampling frequencies $f_{s}$ shown in plots.

values of various statistical parameters averaged over 1-s and 1-min intervals, respectively. The parameters considered over a 10-min interval were peak and mean velocities ( $\hat{U}_{10 \min }$ and $\bar{U}_{10 \min }$, respectively), mean wind direction $\left(\alpha_{10 \mathrm{~min}}\right)$, gust factor $\left(G_{10 \mathrm{~min}}=\hat{U}_{10 \mathrm{~min}} / \bar{U}_{10 \mathrm{~min}}\right)$, turbulence intensity $\left(I_{10 \mathrm{~min}}\right)$, skewness $\left(\gamma_{10 \mathrm{~min}}\right)$, and kurtosis $\left(k_{10 \mathrm{~min}}\right)$, as well as the same set of parameters for a 1-h interval (except for the peak velocity). If $\hat{U}_{10 \min } \geq 15 \mathrm{~m} \mathrm{~s}^{-1}$, the wind record is a candidate to be a thunderstorm wind. Also, if $G_{10 \mathrm{~min}} / G_{10 \text { min_ref }}>1.25$ [ $G_{10 \text { min_ref }}$ is the reference gust factor obtained from ESDU (1993)], then the event is either nonstationary and non-Gaussian (i.e., thunderstorm wind) or stationary and non-Gaussian (i.e., intermediate wind). Last, whether such an event is a thunderstorm or intermediate wind is later determined qualitatively. The methodology proposed in this paper could be used to carry out this separation procedure automatically.

Lombardo (2009), Lombardo et al. (2014), and Gunter et al. (2017) investigated individual time series of thunderstorm winds by analyzing abrupt changes in wind speed and direction records. The segmentation method proposed in Lombardo et al. (2014) identifies abrupt changes in wind speed records by inspecting statistically significant changes in variance using the reverse arrangement test (Kendall et al. 1983) and run test (Brownlee 1965; 
Bendat and Piersol 2010). In this approach, the beginning of time series is split into eighteen 3-s segments that are subjected to stationarity testing. If the test statistics of the portion of the time series were stationary, the algorithm includes the following 3-s interval and repeats the stationarity testing. This addition of the following (3-s) portion to the previous length of the segment is carried out until one or both tests indicate nonstationarity, which is then deemed as a changepoint in the time series. More recently, Gunter et al. (2017) separated the time series of thunderstorm winds into five segments identified in a $40-\mathrm{s}$ moving average of the wind direction record. Their method is based on identifying the zeroderivative points on either side of the abrupt change in the moving average. The physical justification of the methodology follows from the studies of Goff (1976) and Wakimoto (1982) that describe the kinematics of thunderstorm outflows through a sequence of gust surges each characterized by changes in wind speed and direction (Lompar et al. 2018). In this study, we propose a new segmentation method for the following reasons. First, the reverse arrangement method detects the mean trends only (Pan and Patton 2017), whereas thunderstorm winds are accompanied by changes in wind fluctuations in addition to the changes of mean flow. Second, while the run test inspects a combination of mean and periodic variations in time series, it is not capable of distinguishing between the variations in mean from the variations in periodic trends. The wind direction approach, on the other hand, assumes that thunderstorm velocity records are always associated with the changes in wind direction. While this assumption is usually accurate, some anemometer records of thunderstorm winds do not exhibit sudden shifts in wind direction. This point will be demonstrated later in section 3 .

This article investigates abrupt changes in wind speed records of thunderstorm winds with the goal of describing the transient nature of the phenomena using objective procedures that facilitates automated data analysis. Since the analysis is currently restricted to wind speed data, the paper aims to identify regions with different wind characteristics by disregarding other atmospheric variables (e.g., temperature, pressure, relative humidity). The introduced methodology, however, could be applied to the analysis of other thunderstorm variables (Lompar et al. 2018), and not just wind speed. The presented method for the analysis of abrupt changes in wind speed records is adopted from signal processing carried out in the fields of speech recognition and brain research (Basseville and Nikiforov 1993; Darkhovski 1994; Lavielle 2005), as well as geosciences (Killick et al. 2012). Recently, Romanic et al. (2019) used the same method to investigate the transient features of experimentally produced downburst-like impinging jets in cross-flow. The method was applied to detect the onset of impinging jets and to find the velocity slowdown in crossflows. The present paper extends the applicability of this methodology to real thunderstorm winds. The current study also investigates a large set of thunderstorm events from different geographic and climate regions around the world. As discussed in Markowski and Richardson (2010) and Lompar et al. (2017), the natural variability in cloud dynamics and microphysics between different climate regions can affect precipitation characteristics and gust front dynamics. For example, most of the U.S. thunderstorm records analyzed in this study are associated with supercell or bow echo thunderstorms, while the majority of European data came from less organized thunderstorms.

The objectively analyzed and segmented thunderstorm velocity records can be of importance in wind energy and wind engineering (Solari 2016). For example, an analysis of structural responses to transient winds is typically carried out via the thunderstorm response spectrum technique (Solari 2016), whereas the structural responses to $\mathrm{ABL}$ winds are analyzed through the gust response factor technique (e.g., Davenport 1961; Solari 1983). For the former method, the transient characteristics of the velocity record are expressed through the slowly varying mean and the residual fluctuations (e.g., Choi and Hidayat 2002; Chen and Letchford 2004, 2006; Holmes et al. 2008; Solari et al. 2015; Burlando et al. 2017; Junayed et al. 2019). The proposed methodology in this study can be used to objectively separate different segments in thunderstorm velocity records and therefore facilitate the proper interpretation of obtained structural responses. In addition to the analysis of abrupt changes in the instantaneous wind speed records, this paper also investigates the transient features of the decomposed velocity records. Moreover, an attempt will be made to relate the transient nature of the instantaneous wind speed to the transient features of the decomposed time series (e.g., moving-mean and turbulent fluctuations). These findings will be discussed in terms of surface roughness and anemometer height above ground.

\section{Data and methods}

\section{a. Data}

Thunderstorm events analyzed in this study come from a variety of sources and cover three continents: Europe (9 events), North America (9), and Australia (1) (Fig. 2). Normalized time series of velocity records from all thunderstorm events are depicted in Fig. 3. Eight events from Europe are from two European Union projects "Wind and Ports" (Solari et al. 2012) and 
(a)

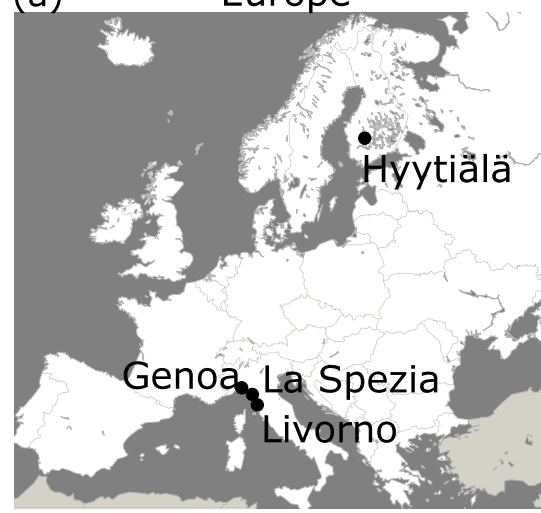

(b)

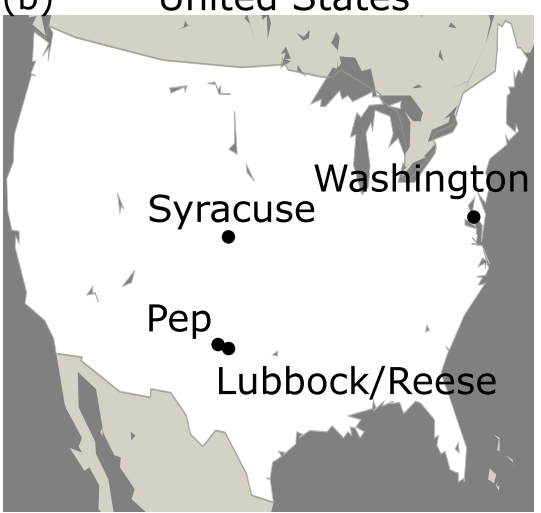

(c)

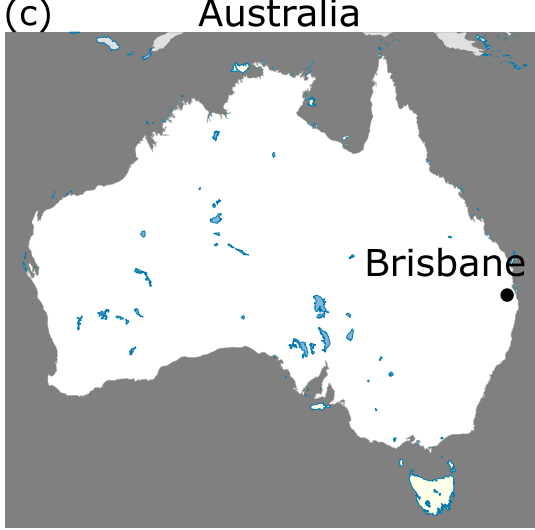

FIG. 2. The geographic origin of thunderstorm wind records investigated in this study.

"Wind, Ports and Sea" (Repetto et al. 2018) (Figs. 3b-i). The goal of these projects was to provide high-quality field measurements of thunderstorm winds in the Ligurian Sea and the north Tyrrhenian Sea, in the Mediterranean (Fig. 2a). Out of eight events from this region (Italy), one event was recorded in Genoa, four were measured in $\mathrm{La}$ Spezia, and three were from Livorno. Some events were captured with several anemometers making the number of analyzed velocity records larger than the number of considered events. Anemometer characteristics and site coordinates are provided in Table 1 and Fig. 4. The remaining event from Europe was observed in Finland (Järvi et al. 2007) in 2004 (Table 1 and Figs. 2a, 3a). The events from the Mediterranean correspond to thunderstorm winds with mostly marine exposure, while the thunderstorm in Finland is an event that took place above a forest area. Thus, there is a significant difference between surface roughness of the two regions in addition to the profoundly different climatological characteristics of Finland (northeast Europe) and the Mediterranean coast of Italy (south Europe).

Figure $2 b$ shows the location of thunderstorm winds investigated in the United States. Two events were recorded in Texas-one in Pep (Gunter et al. 2017) (Fig. 3k) and another in Lubbock (Orwig and Schroeder 2007; Holmes et al. 2008) (Fig. 3m). The Lubbock downburst was recorded by twelve anemometers (six masts), which makes it the best-documented downburst event in this study. Another event from the United States was recorded in Syracuse, Kansas, (Gunter and Schroeder 2015) (Fig. 31) and one at Andrews Air Force Base (AAFB) in Maryland near Washington, D.C. (Fujita 1985) (Fig. 3j). The downburst in Washington, reported by Fujita (1985), is still one of the strongest, if not the strongest, with the peak velocity of $68 \mathrm{~m} \mathrm{~s}^{-1}$ measured at only $4.9 \mathrm{~m}$ above ground. The original anemometer measurements for the Washington event were not available to the authors, and therefore the published time series in Fujita (1985) was digitized (Rohatgi 2019) in order to obtain wind speed data. The uncertainty of digitized data is larger than the real measurements. Another set of five thunderstorm events from the Lubbock-Reese (Texas) was obtained from Lombardo et al. (2014) (Table 1).

The single downburst event from Australia was observed by Sherman (1987) in the suburban region of Brisbane (Figs. 2c, 3s). Similar to Fujita (1985), raw data for this event were not available, and thus the analyzed time series were digitized (Rohatgi 2019). Overall, the number of thunderstorm events investigated in this study is 19 , while the total number of velocity records is 42 .

Surface roughness characteristics surrounding the measuring site were acquired using Google Earth Pro aerial imagery (Fig. 4). The white dashed circles in Fig. 4 have a diameter of $10 \mathrm{~km}$, with the measurement site being close to the center of the circles. The values of roughness length $z_{0}$ were either obtained from the literature that originally published the events (e.g., Lombardo et al. 2014; Gunter et al. 2017) or they were estimated by combining the aerial imagery with the exposure categories provided in ESDU documentation (Table 2). The uncertainties of $z_{0}$ estimates using different methods are discussed in Romanic et al. (2018). The anemometers in Italy (GE, LS, and LI; see Table 1 for abbreviations) were located along the coast and the $z_{0}$ values are provided for land and sea separately. Other anemometers that recorded the data for this study were installed on land and mostly with uniform roughness surrounding the site (HY, SY, PE, and BR). In the cases of nonuniform roughness, the values of $z_{0}$ for different wind direction sectors are provided in Table 2.

\section{b. Changepoints in wind records-Theoretical background}

Informally, changepoints represent the points in the time series at which statistical properties of a segment of 


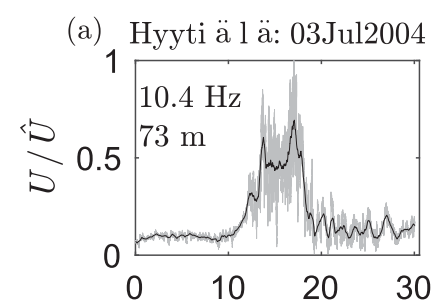

(e) LaSpezia : 19Apr2012
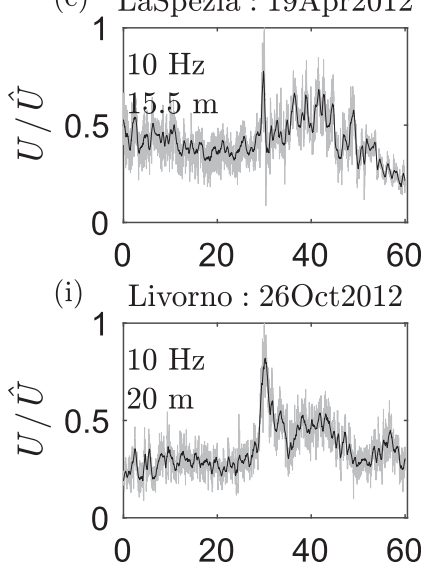

(m) Lubbock : 04Jun2002

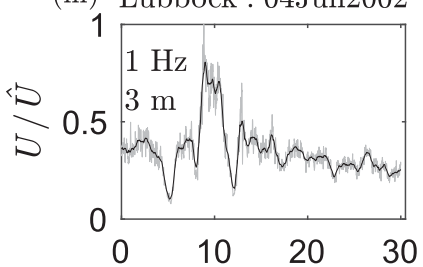

(q) Lubbock : 04Jun2009

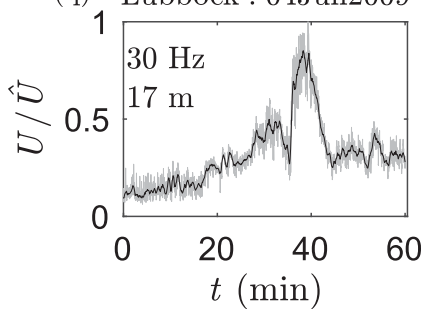

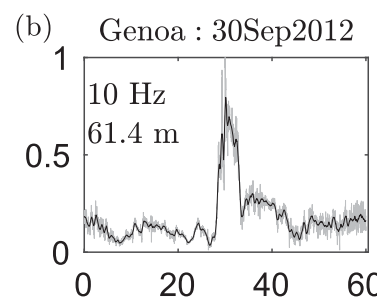

(f) LaSpezia : 25Oct2011

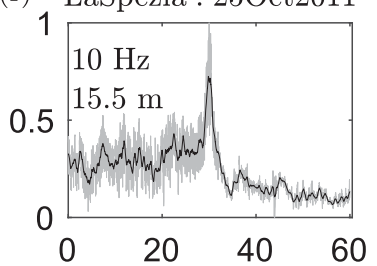

(j) Washington : 01Aug1983

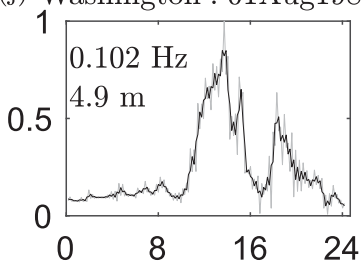

(n) Lubbock : 24Aug2007

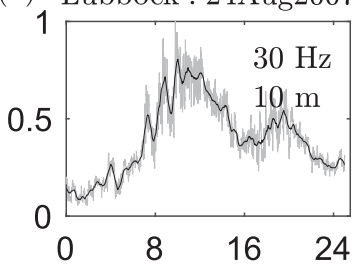

(r) Lubbock : 14May2008

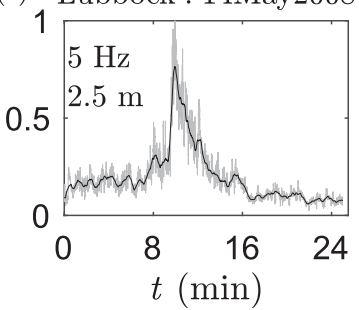

(c) LaSpezia : 05Jun2011

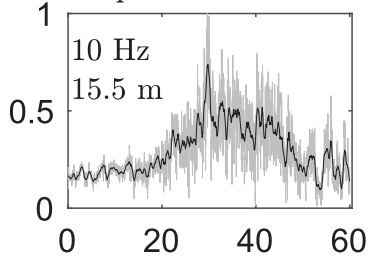

(g) Livorno : 01Oct2012

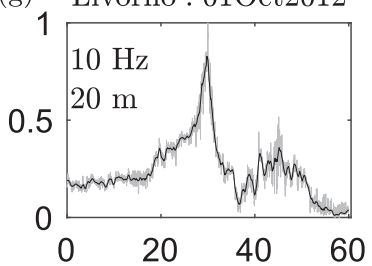

(k) Pep : 05Jun13

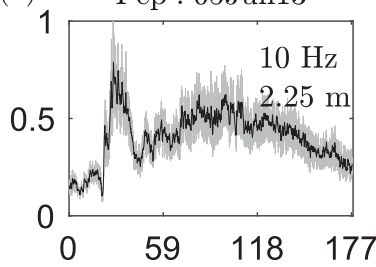

(o) Lubbock : 21May2008

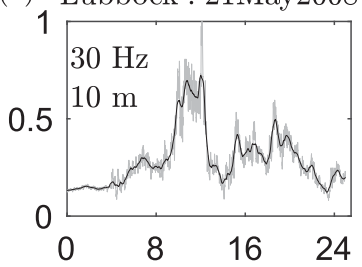

(s) Brisbane : 05Nov1977

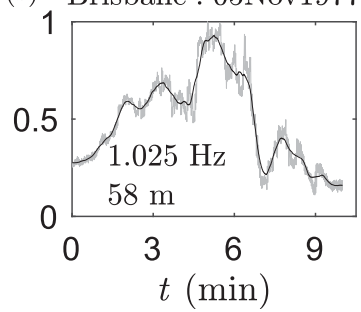

(d) LaSpezia : 11Apr2012

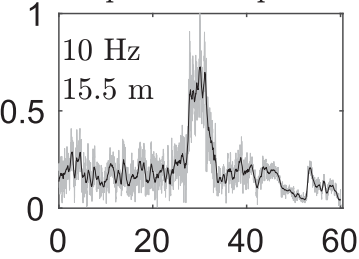

(h) Livorno : 04Sep2011

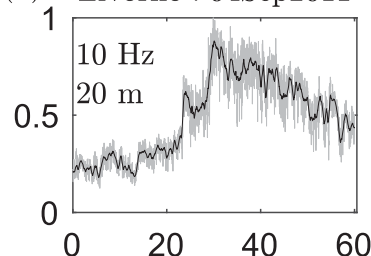

(1) Syracuse : 11Jun2011

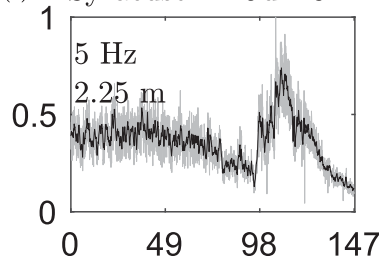

(p) Lubbock : 19Jun2008

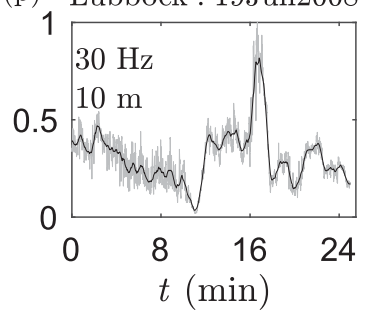

FIG. 3. All thunderstorm events investigated in this study. Gray and black lines are instantaneous wind speeds and their 30-s moving means, respectively. Anemometer sampling frequency $(\mathrm{Hz})$ and height $(\mathrm{m})$ shown in each plot. In the case of multiple anemometers that recorded the event, only the velocity record from anemometer 1 is plotted. All velocities are normalized with the peak velocity $\hat{U}$.

observations change. Formally, a changepoint can be defined as follows. Consider a time series $U_{t}=\left(U_{1}, U_{2}, \ldots\right.$, $U_{T}$ ) of velocity data (e.g., Fig. 1), where $T$ is the length of the record. That is, $T=\Delta T f_{s}$, where $\Delta T$ is the length of time between measurements (s) and $f_{s}$ is the sampling frequency $(\mathrm{Hz})$. A changepoint occurs if at any time $\tau \in\{1,2, \ldots, T-1\}$ some statistical properties of $\left\{U_{1}, \ldots, U_{\tau}\right\}$ and $\left\{U_{\tau+1}, \ldots, U_{T}\right\}$ change. The above definition can readily be extended to a set of changepoints $m$, with their respective positions being $1<\tau_{1}<\tau_{2}<\cdots<\tau_{m}<T$.
In changepoint detection problems, the goal is to minimize the expression (Lavielle 1999, 2005; Killick et al. 2012):

$$
\sum_{i=1}^{m+1}\left[\mathscr{C}\left(U_{\left(\tau_{i-1}+1\right): \tau_{i}}\right)+\gamma\right]
$$

where $\mathscr{C}($.$) is a cost function for segments \tau_{i-1}$ and $\tau_{i}$, and $\gamma$ is a penalty function against overfitting. In this study, the minimization is performed using a recursive approach (Killick et al. 2012): 
TABLE 1. Thunderstorm wind events investigated in this study.

\begin{tabular}{|c|c|c|c|c|c|c|}
\hline No. & Country & Anemometer location & Event date & $\begin{array}{l}\text { Anemometer } \\
\text { height AGL (m) }\end{array}$ & $\begin{array}{c}\text { Sampling } \\
\text { frequency }(\mathrm{Hz})\end{array}$ & Reference study \\
\hline 1 & Finland & Hyytiälä (HY) & 3 Jul 2004 & 73 & 10.4 & Järvi et al. (2007) \\
\hline 2 & \multirow[t]{17}{*}{ Italy } & Genoa (GE) & 30 Sep 2012 & 61.4 & 10 & De Gaetano et al. (2014); \\
\hline 3 & & \multirow[t]{4}{*}{ La Spezia (LS) } & 5 Jun 2011 & 15.5 & & Burlando et al. $(2017,2018)$ \\
\hline 4 & & & 11 Apr 2012 & & & \\
\hline 5 & & & 19 Apr 2012 & & & \\
\hline 6 & & & 25 Oct 2011 & & & \\
\hline 7 & & \multirow[t]{12}{*}{ Livorno (LI) } & 1 Oct 2012 & 20 & & \\
\hline 8 & & & & & & \\
\hline 9 & & & & & & \\
\hline 10 & & & 4 Sep 2011 & & & \\
\hline 11 & & & & & & \\
\hline 12 & & & & & & \\
\hline 13 & & & & & & \\
\hline 14 & & & & 75 & & \\
\hline 15 & & & 26 Oct 2012 & 20 & & \\
\hline 16 & & & & & & \\
\hline 17 & & & & & & \\
\hline 18 & & & & & & \\
\hline 19 & \multirow[t]{20}{*}{ United States } & Syracuse (SY) & 11 Jun 2011 & 2.25 & 5 & $\begin{array}{l}\text { Gunter and Schroeder (2015); } \\
\text { Gunter et al. (2017) }\end{array}$ \\
\hline 20 & & Pep (PE) & 5 Jun 2013 & 2.25 & 10 & Gunter et al. (2017) \\
\hline 21 & & \multirow[t]{17}{*}{ Lubbock (LU) } & 4 Jun 2002 & 3 & 1 & \multirow{12}{*}{$\begin{array}{l}\text { Orwig and Schroeder (2007); } \\
\text { Holmes et al. (2008) }\end{array}$} \\
\hline 22 & & & & 10 & & \\
\hline 23 & & & & 15 & & \\
\hline 24 & & & & 10.1 & & \\
\hline 25 & & & & 6.1 & & \\
\hline 26 & & & & 4 & & \\
\hline 27 & & & & 2.1 & & \\
\hline 28 & & & & 10 & & \\
\hline 29 & & & & 6 & & \\
\hline 30 & & & & 4 & & \\
\hline 31 & & & & 10 & & \\
\hline 32 & & & & 3 & & \\
\hline 33 & & & 24 Aug 2007 & 10 & 30 & \multirow[t]{5}{*}{ Lombardo et al. (2014) } \\
\hline 34 & & & 21 May 2008 & 10 & 30 & \\
\hline 35 & & & 19 Jun 2008 & 10 & 30 & \\
\hline 36 & & & 4 Jun 2009 & 17 & 30 & \\
\hline 37 & & & 14 May 2008 & 2.5 & 5 & \\
\hline 38 & & Washington, D.C. (WA) & 1 Aug 1983 & 4.9 & 0.1 & Fujita (1985) \\
\hline 39 & \multirow[t]{3}{*}{ Australia } & \multirow[t]{3}{*}{ Brisbane (BR) } & \multirow[t]{3}{*}{5 Nov 1977} & 58 & 1.025 & \multirow{3}{*}{ Sherman (1987) } \\
\hline 40 & & & & 104 & 1.14 & \\
\hline 41 & & & & 10 & 0.196 & \\
\hline
\end{tabular}

$$
F(s)=\min _{t<s}\left[F(t)+\mathscr{C}\left(U_{(t+1): s}\right)+\gamma\right],
$$

where $F(s)$ is the optimal partitioning of the points $U_{1}, U_{2}, \ldots, U_{s}(s=1,2, \ldots, T)$ and $F(t)$ is the optimal partitioning of the points $U_{1}, U_{2}, \ldots, U_{t}$, where $t<s$ and $F(0)=-\gamma$. Details of this computational algorithm-the so-called optimal partitioning method-are described in Jackson et al. (2005) and Lavielle (2005), with improvements in computational efficiency using the prude exact linear-time method proposed by Killick et al. (2012). Equation (2) shows that the penalty constant $\gamma$ is a "balance" between the cost function and the number of changepoints. If $\gamma=$ 0 , there is no penalty for adding a changepoint to the model and, therefore, the data are segmented in as many segments as possible (i.e., $T-1$ segments). The relationship between $\gamma$ and $m$ depends on the properties of data, and it will be discussed more in section $3 \mathrm{~d}$ based on the results obtained from the analyzed velocity records. In general terms, however, Eq. (2) demonstrates that a larger $\gamma$ results in fewer changepoints and thus smaller variance of the model. Since the variance describes the sensitivity of the model to input data, the small variance also results in a 

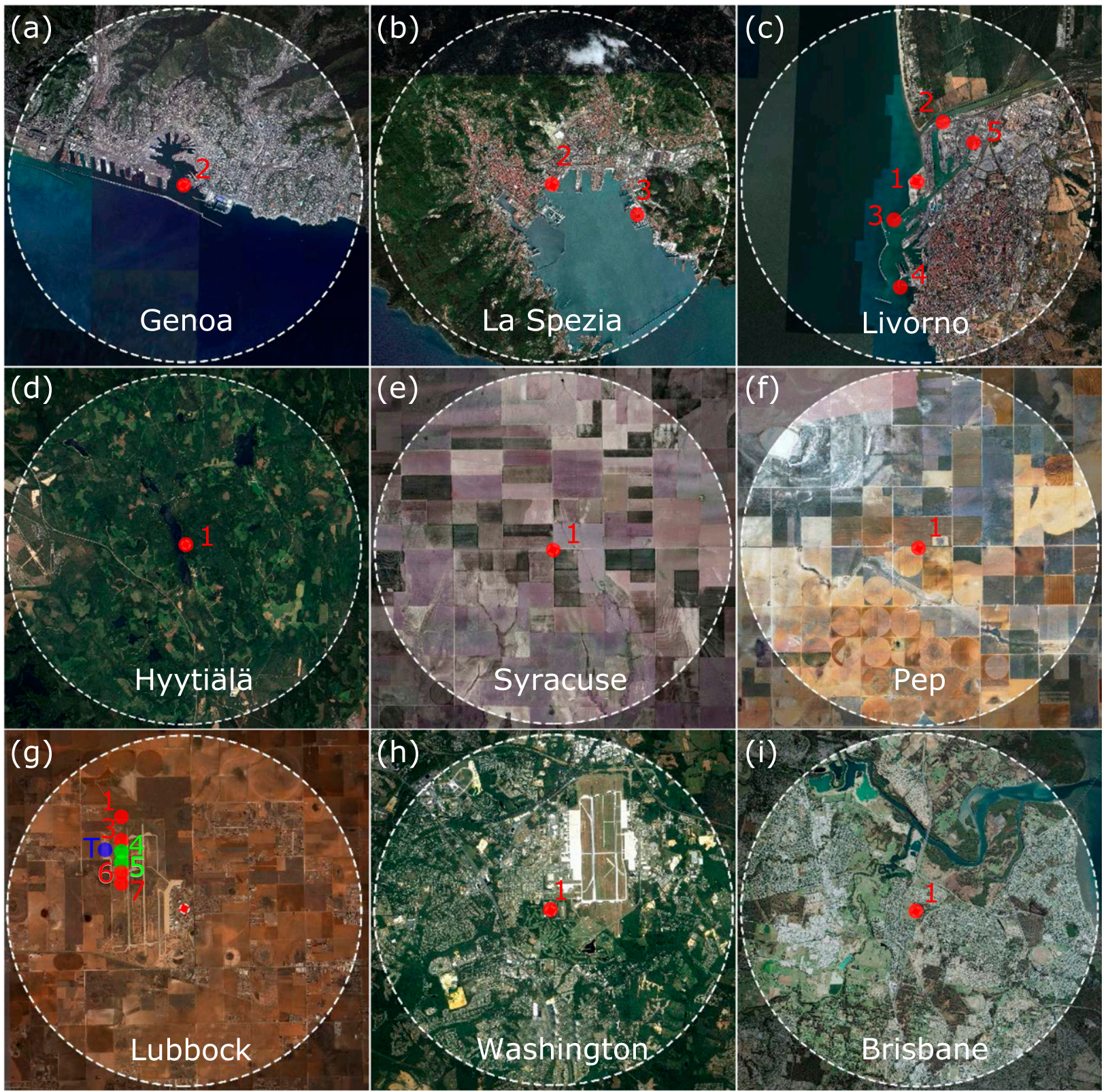

FIG. 4. Aerial imagery showing the terrain surrounding the measuring sites (source: Google Earth Pro). In all cases, the red dot 1 shows the position of anemometer 1 (see Tables 1 and 2 for details).

more substantial bias of the model. So, in other words, $\gamma$ is a trade-off between bias and variance of $F(s)$.

The next step is to describe the cost functions used in this study. Let us again consider the time series $U_{t}=\left(U_{1}\right.$, $\left.U_{2}, \ldots, U_{T}\right)$ and, supported by the central limit theorem, let us further assume that the time series is a result of an independent normal stochastic process (Chen and Gupta 2012). Therefore, $U_{i}$ can be modeled as

$$
U_{i}=c_{0, j}+c_{1, j} t_{i}+\varepsilon_{i},
$$

where $t_{i}(i=1,2, \ldots, T)$ is the time, $\varepsilon_{i}$ is the noise (error term with zero mean and unit variance), and $c_{0, j}$ and $c_{1, j}$ are the linear regression coefficients of the segment $j$. In other words, $U_{i}$ is a subset of a random variable $\mathcal{U}_{i}$ whose Gaussian probability density function $f_{\mathcal{U}_{i}}$ is

$f_{\mathcal{U}_{i}}\left(U_{i} \mid t_{i}, c_{0, j}, c_{1, j}, \sigma_{j}^{2}\right)=\frac{1}{\sqrt{2 \pi \sigma_{j}^{2}}} \exp \left[\frac{-\left(U_{i}-c_{0, j}-c_{1, j} t_{i}\right)^{2}}{2 \sigma_{j}^{2}}\right]$, 
TABLE 2. Aerodynamic roughness length $z_{0}$ around measuring sites estimated using aerial imagery in Fig. 4 and literature.

\begin{tabular}{llc}
\hline \hline \multirow{2}{*}{ Site location } & \multicolumn{1}{c}{ Land } & \multicolumn{1}{c}{$z_{0}(\mathrm{~m})$} \\
\cline { 2 - 3 } & \multicolumn{1}{c}{ Water } \\
Genoa, Italy & 4 (rugged hilly terrain) & $10^{-3}$ (large expansion of water) \\
La Spezia, Italy & 4 (rugged hilly terrain) & $10^{-3}$ (large expansion of water) \\
Livorno, Italy & 0.05 (farmland) to 0.6 (center of small towns) & $10^{-3}$ (large expansion of water) \\
Hyytiälä, Finland & 0.5 (fairly level wooded country) & - \\
Syracuse, KS & 0.01 (fairly level grass plains) & - \\
Pep, TX & 0.01 (fairly level grass plains) (Gunter et al. 2017) & - \\
Lubbock, TX & 0.01 (fairly level grass plains) (Lombardo et al. 2014) & - \\
Washington, D.C. & $4 \times 10^{-3}$ (airport) to 0.3 (suburbs) & - \\
Brisbane, Australia & 0.3 (suburbs) & - \\
\hline
\end{tabular}

where $\sigma^{2}$ is the variance. Invoking the assumption of data independency once more, the likelihood function $L$ of all data $U_{t}=\left(U_{1}, U_{2}, \ldots, U_{T}\right)$ is the product of the $f_{\mathcal{U}_{i}}$ :

$$
\begin{aligned}
L\left(\bar{C}_{0}, \bar{C}_{1}, \bar{\sigma}^{2}\right)= & \prod_{j=1}^{m+1} \prod_{i=\tau_{j-1}+1}^{\tau_{j}} \frac{1}{\sqrt{2 \pi \sigma_{j}^{2}}} \\
& \times \exp \left[\frac{-\left(U_{i}-c_{0, j}-c_{1, j} t_{i}\right)^{2}}{2 \sigma_{j}^{2}}\right],
\end{aligned}
$$

where $\bar{C}_{0}=\left(c_{0,1}, c_{0,2}, \ldots, c_{0, m+1}\right), \quad \bar{C}_{1}=\left(c_{1,1}, c_{1,2}, \ldots\right.$, $\left.c_{1, m+1}\right)$, and $\bar{\sigma}^{2}=\left(\sigma_{1}^{2}, \sigma_{2}^{2}, \ldots, \sigma_{m+1}^{2}\right)$. The unbiased maximum likelihood estimates of the unknown parameters in Eq. (5) are the solution to the following system of algebraic equations (Neter et al. 1996):

$$
\begin{aligned}
& \hat{C}_{0, j}=\bar{U}_{i}-\hat{C}_{1, j} \bar{t}_{i}, \\
& \hat{C}_{1, j}=\frac{\sum_{i=\tau_{j-1}+1}^{\tau_{j}}\left(t_{i}-\bar{t}_{i}\right)^{2}\left(U_{i}-\bar{U}_{i}\right)^{2}}{\sum_{i=\tau_{j-1}+1}^{\tau_{j}}\left(t_{i}-\bar{t}_{i}\right)^{2}}, \\
& \hat{\sigma}_{j}^{2}=\frac{1}{\tau_{j}-\tau_{j-1}-2} \sum_{i=\tau_{j-1}+1}^{\tau_{j}}\left(U_{i}-c_{0, j}-c_{1, j} t_{i}\right)^{2},
\end{aligned}
$$

where $\bar{t}_{i}=1 / \tau_{j}-\tau_{j-1} \sum_{i=\tau_{j-1}+1}^{\tau_{j}} t_{i} \quad$ and $\quad \bar{U}_{i}=1 / \tau_{j}-\tau_{j-1}$ $\sum_{i=\tau_{j-1}+1}^{\tau_{j}} U_{i}$. It is beneficial to introduce twice the negative log-likelihood function as a choice of the cost function in order to directly add segment costs to the overall cost (Horvath 1993). Therefore, we cast Eq. (5) in the form:

$$
\mathscr{C}\left[U_{\left(\tau_{j-1}\right): \tau_{j}}\right]=-2 \ln \left[L\left(\hat{C}_{0, j}, \hat{C}_{1, j}, \hat{\sigma}_{j}^{2}\right)\right],
$$

or after expanding the right-hand side:

$$
\begin{aligned}
\mathscr{C}\left[U_{\left(\tau_{j-1}\right): \tau_{j}}\right]= & \left(\tau_{j}-\tau_{j-1}\right) \ln \left(2 \pi \hat{\sigma}_{j}^{2}\right) \\
& +2 \sum_{i=\tau_{j-1}+1}^{\tau_{j}} \frac{\left(U_{i}-\hat{c}_{0, j}-\hat{c}_{1, j} t_{i}\right)^{2}}{2 \hat{\sigma}_{j}^{2}} .
\end{aligned}
$$

Equation (10) represents the likelihood linear regression cost function. By setting $\hat{c}_{1}=0$, we retrieve the likelihood mean cost function:

$$
\begin{aligned}
\mathscr{C}\left[U_{\left(\tau_{j-1}\right): \tau_{j}}\right]= & -\left(\tau_{j}-\tau_{j-1}\right) \ln \left(2 \pi \hat{\sigma}_{j}^{2}\right) \\
& +2 \sum_{i=\tau_{j-1}+1}^{\tau_{j}} \frac{\left(U_{i}-\hat{c}_{0, j}\right)^{2}}{2 \hat{\sigma}_{j}^{2}} .
\end{aligned}
$$

When analyzing the abrupt changes in the mean wind speed, the standard deviation $\sigma$ (square root of the variance) is a fixed constant in the above expression. Similarly, when investigating the changepoints through $\sigma$ the mean is a fixed constant (Chen and Gupta 2012). Knowing that constant terms do not contribute to the result of minimization or maximization problems, the exact value of any constant is irrelevant. Changepoints in the mean and standard deviation statistics are hereafter referred to as the M and SD changepoints, respectively.

\section{c. Velocity decomposition}

In contrast to the classical Reynolds decomposition that applies to stationary ABL winds (Fig. 1), transient wind records are usually analyzed via (e.g., Choi and Hidayat 2002; Chen and Letchford 2004; Holmes et al. 2008; Solari et al. 2015; Burlando et al. 2017):

$$
U(t)=\bar{U}(t)+U^{\prime}(t),
$$

where $\bar{U}(t)$ is the slowly varying wind speed associated with the low-frequency content of $U(t)$, and $U^{\prime}(t)$ is the residual fluctuations. By further decomposing the residual fluctuations as 


$$
U^{\prime}(t)=\sigma_{U}(t) \tilde{U}^{\prime}(t)
$$

where $\sigma_{U}(t)$ is the slowly varying standard deviation of $U(t)$, and $\tilde{U}^{\prime}(t)$ is the reduced residual turbulent fluctuations, we cast Eq. (12) in the form:

$$
U(t)=\bar{U}(t)\left[1+I_{U}(t) \tilde{U}^{\prime}(t)\right]
$$

where

$$
I_{U}(t)=\frac{\sigma_{U}(t)}{\bar{U}(t)}
$$

is the slowly varying turbulence intensity. The extraction of $\bar{U}(t)$ from $U(t)$ is carried out using a moving mean filter with the averaging window of 30 s (Solari et al. 2015; Burlando et al. 2017).

To investigate the abrupt changes in different scales of motion of thunderstorm winds, the proposed method in this study is applied to the large scales $\bar{U}(t)$ and the intermediate scales of motion $\sigma_{U}(t)$ (Chen and Letchford 2004), as well as the small scales of random turbulence $\tilde{U}^{\prime}(t)$. The objective is to investigate the contributing factors and governing scales of motion that drive the observed changes in the instantaneous wind speed records $U(t)$.

\section{Results and discussion}

\section{a. Abrupt changes in velocity records}

\section{1) EuRope}

The instantaneous velocity records $U(t)$ of several thunderstorm events from Europe are consistently divided into three or four segments using the mean (M) and standard deviation (SD) segmentation statistics (Fig. 5). Nonstationarity in the M statistics occurs only in the $\bar{U}(t)$ and $U(t)$ records, whereas the SD segmentation is observed in $U^{\prime}(t), \sigma_{U}(t)$, and $I_{U}(t)$ in addition to $\bar{U}(t)$ and $U(t)$. The same model settings (i.e., same $\gamma$ values) are applied to all decomposed and instantaneous velocity records for a given event. Overall, the SD segments that encompass the central peak in the $U(t)$ records are the same length or slightly longer than the corresponding segments obtained by applying the M statistics. Only in the cases of LS of 19 April 2012 (Fig. 5e) and 25 October 2011 (Fig. 5f), the number of $M$ and SD segments differ in such a way that the SD approach introduces an additional segment into $U(t)$. However, the central velocity peak has the same duration in terms of both $\mathrm{M}$ and SD analyses. While this result suggests that the $U(t)$ records exhibit similar M and SD changepoints, this finding is not observed in all records analyzed in the present study. Figure 5 further shows that the changepoints in $\bar{U}(t)$ occur at the same time as in the $U(t)$ records. Since $\bar{U}(t)$ represents the contribution of large-scale flow structures that govern $U(t)$; it is expected that the locations of changepoints in these two velocity records coincide in particular in the case of $\mathrm{M}$ statistic. The rest of the decomposed velocity records do not exhibit any abrupt changes in $\mathrm{M}$ if the same model settings are used as for $U(t)$. Nevertheless, the SD approach identifies the increased wind fluctuations in $\sigma_{U}(t)$ during the thunderstorm peak. The two exceptions from this observation (Figs. 5e,f) are characterized by equally pronounced wind fluctuation in the background wind before the thunderstorm segment. Figure $5 \mathrm{c}$ also shows that the location of changepoints in $\sigma_{U}(t)$ is probably decupled from any roughness changes due to the constant wind direction throughout the event. The wind fluctuations greatly diminished after the thunderstorm passage. In all cases, $\tilde{U}^{\prime}(t)$ is a stationary process without changepoints.

Another feature worth investigating in Fig. 5 is a possible relationship between changepoint locations and wind direction $\alpha$ (i.e., changes in $z_{0}$ ). In the majority of cases, it seems that these parameters are mutually independent. An example where a link between changepoints in $\mathrm{M}$ and $\mathrm{SD}$, on the one hand, and $\alpha(t)$ and $z_{0}$ changes, on the other hand, might exist is the LS event from 11 April 2011 (Fig. 5d). In this case, the increase in $z_{0}$ from 0.003 to $4 \mathrm{~m}$, and the consequent return to $0.003 \mathrm{~m}$ nicely coincides with the total duration of the thunderstorm part of the record. Similarly, the SD method applied to $\sigma_{U}(t)$ in Fig. $5 \mathrm{f}$ splits the record into two parts and the changepoint location matches the time instant of the abrupt change of $z_{0}$.

The LS thunderstorms of 5 June 2011 and 19 April 2012 (Figs. 5c,e) are characterized by relatively constant $\alpha(t)$. These events represent rare instances when the occurrence of thunderstorm wind is not accompanied by significant changes in wind direction. However, both cases have a couple of $\mathrm{M}$ and SD changepoints that separate the central thunderstorm peak from the rest of the record. These events also represent the cases for which the wind direction-based segmentation procedure proposed in Gunter et al. (2017) would not differentiate between a thunderstorm and nonthunderstorm segments. The fewer cases characterized by constant wind direction in this study are expected because a shift in wind direction is one of the main signatures of a thunderstorm passage.

Figures 6 and 7 show the performances of the segmentation method applied to the events that were captured with multiple anemometers. Because such measurements are rare, in particular in Europe, the presented cases enable the analysis of spatiotemporal characteristics of these events, as well as the evaluation of the segmentation method applied to multiple velocity records from the same 
(a)

HY: 3 Jul 2004
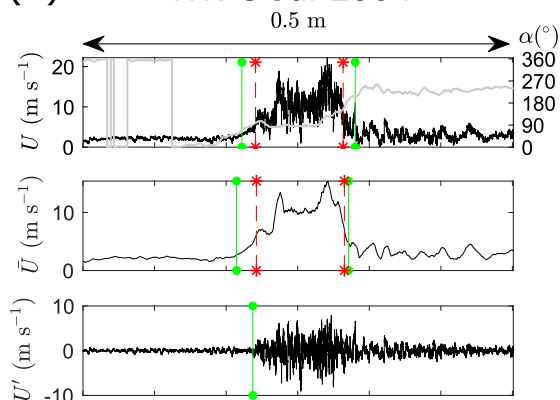

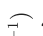
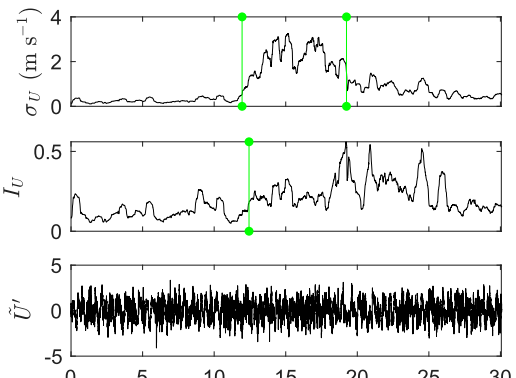

\section{(d)}

LS: 11 Apr 2012
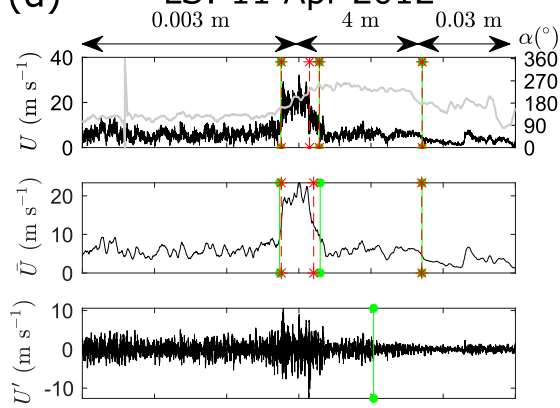

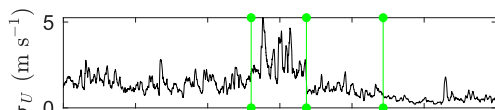

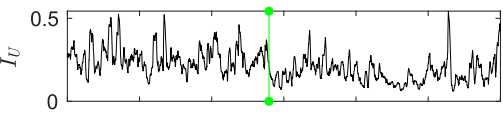

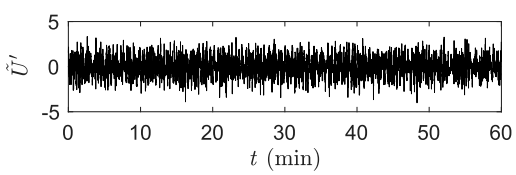

(b) GE: 30 Sep 2012
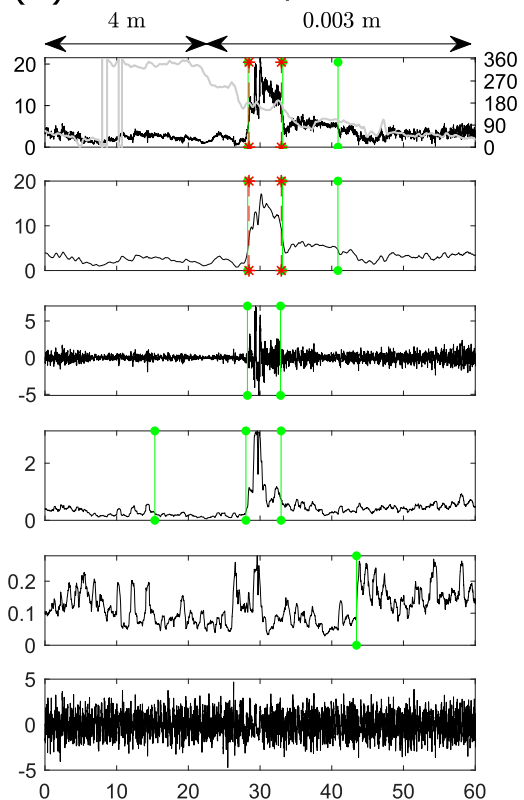

(e) LS: 19 Apr 2012
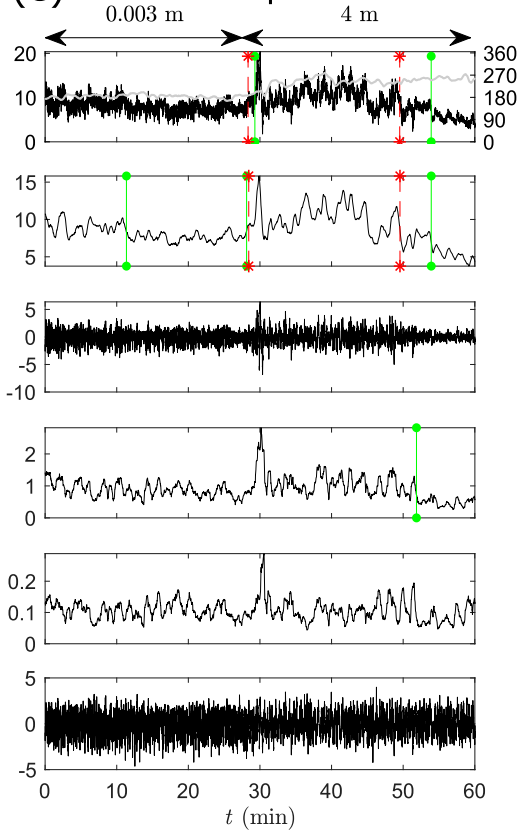

(c) LS: 5 Jun 2011
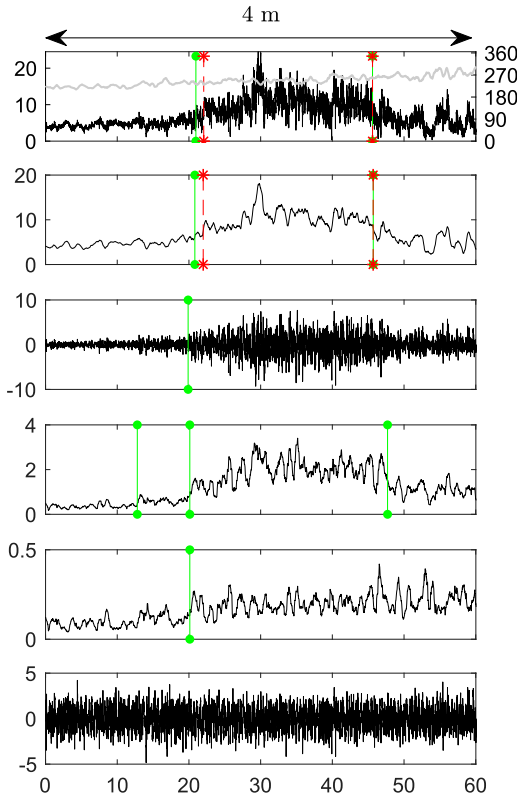

(f) LS: 25 Oct 2011
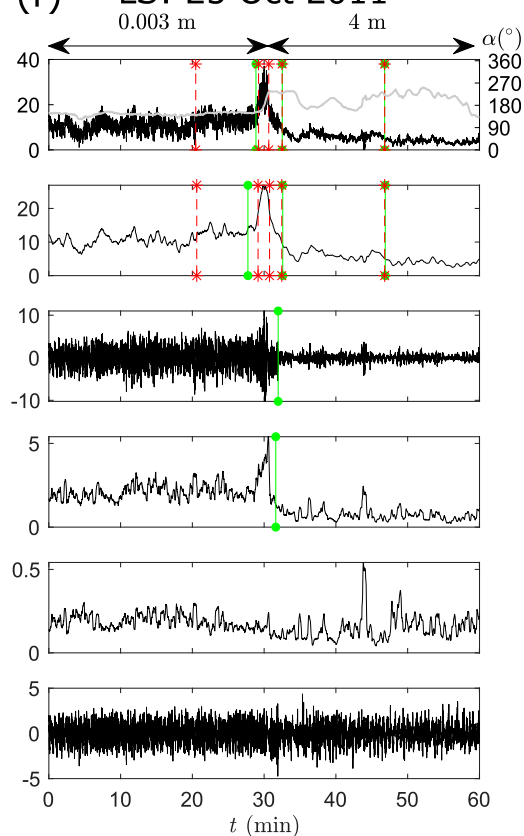

FIG. 5. Changepoints detected using the M (red line) and SD (green line) methods applied to decomposed velocity records of the thunderstorm events from Europe. For each event, the first subplot shows the instantaneous wind speed $U$ (black line) and the 30-s moving mean of wind direction $\alpha$ (gray line; secondary $y$ axis) while the following five subplots depict slowly varying mean $\bar{U}$, residual fluctuations $U^{\prime}$, slowly varying standard deviation $\sigma_{U}$, slowly varying turbulence intensity $I_{U}$, and reduced turbulent fluctuations $\tilde{U}^{\prime}$, in respective order. The values of roughness length $z_{0}$ for different wind direction sectors shown above the first subplot.

event. The LI event from 1 October 2012 (Figs. 6a-c) is characterized by higher values of $I_{U}(t)$ at $75 \mathrm{~m}$ (LI5) than at $20 \mathrm{~m}$ AGL (LI1 and LI3), which is different from the typical turbulence profiles in ABL winds. The high values of $I_{U}(t)$ are caused by the sharp wind spike that occurred approximately $30 \mathrm{~min}$ into the time series (Figs. 6b,c). Because this velocity spike is also present in $\bar{U}(t)$, its existence is associated with the large-scale structures in the outflow (Burlando et al. 2017). In other words, the spike is likely not a random turbulent fluctuation. Burlando et al. 
(a)
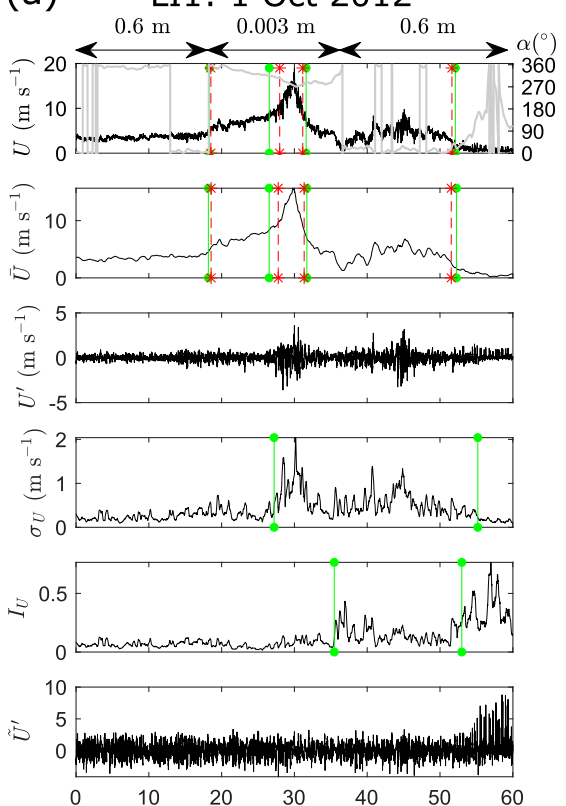

(d)

LI1: 26 Oct 2012
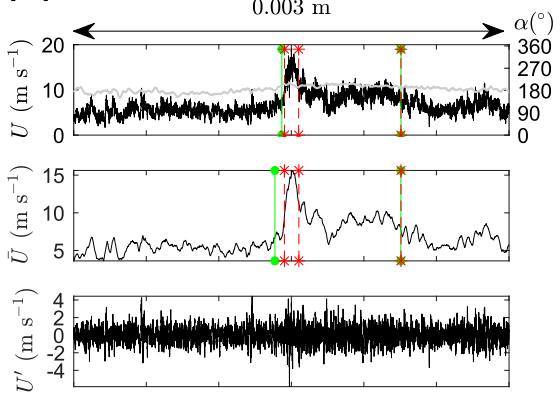

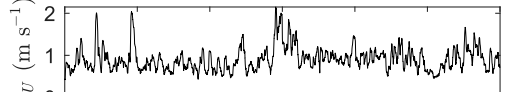

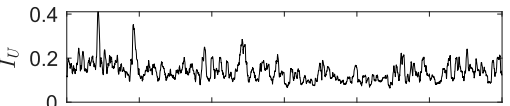

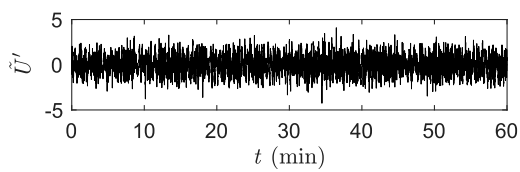

(b)

LI3: 1 Oct 2012
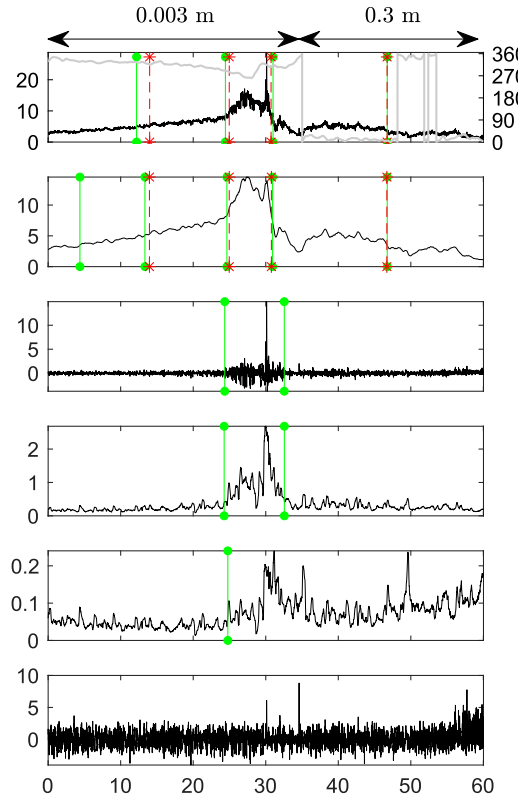

(e) LI3: 26 Oct 2012
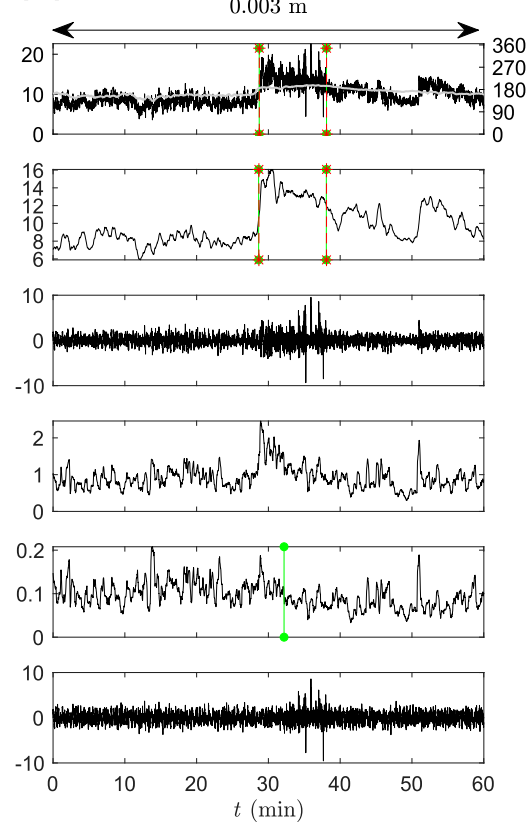

(c) LI5: 1 Oct 2012
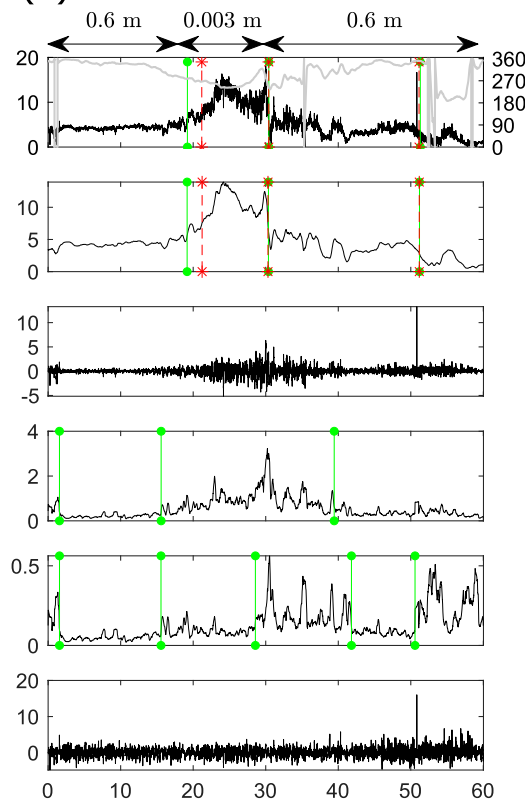

(f) LI4: 26 Oct 2012
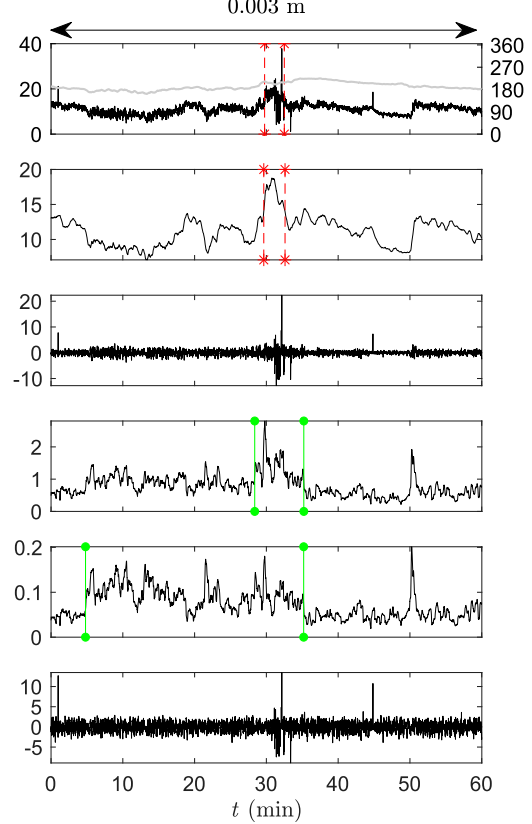

FIG. 6. As in Fig. 5, but for two thunderstorm events from Livorno captured with multiple anemometers.

(2017) discussed that this spike in the anemometer records might represent the occurrence of a smaller-scale burst embedded into the larger-scale downburst (Sherman 1987; Hjelmfelt 1988). The absence of this feature from the LI1 record (Fig. 6a) additionally supports the hypothesis of a highly localized phenomenon.

The $\mathrm{M}$ and SD changepoints in the $U(t)$ and $\bar{U}(t)$ nearly overlap, except for an additional SD changepoint that appears in $U(t)$ from the LI3 anemometer (Fig. 6b). The second segment in $U(t)$ is associated with the steady increase of wind speed prior to the thunderstorm peak, and this phenomenon is sometimes discussed in terms of a gust front that precedes the thunderstorm (Droegemeier and Wilhelmson 1987; Mueller and Carbone 1987). However, the gust front feature is not observed in all velocity records. The relationship between $\alpha(t)$ and $z_{0}$, 
(a)
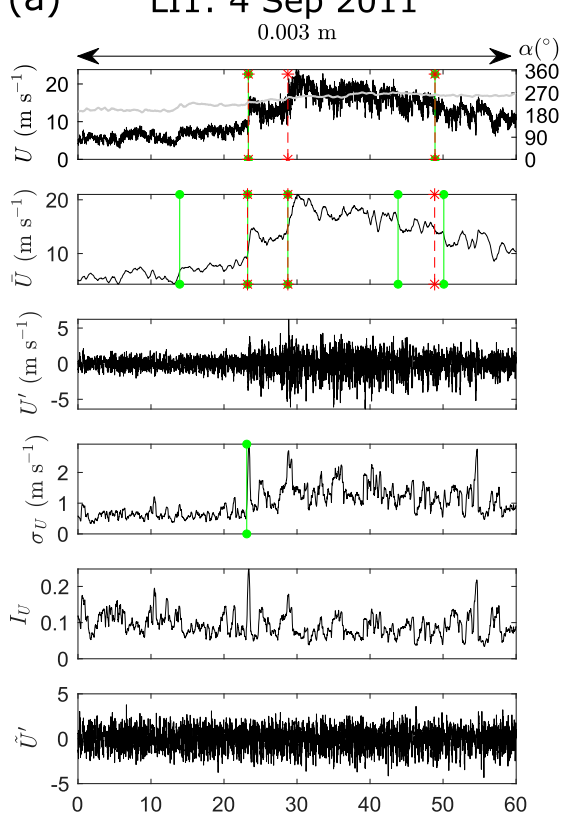

\section{(d)}

\section{LI4: 4 Sep 2011}
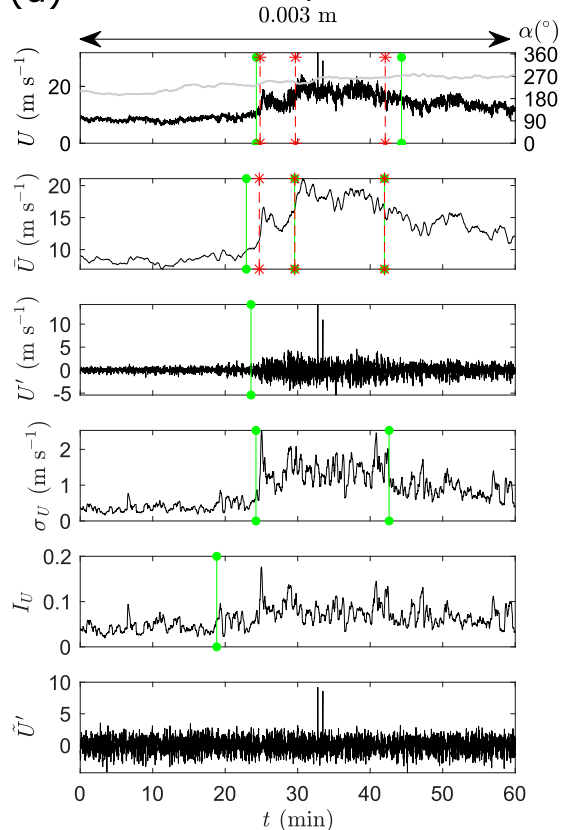

(b)

LI2: 4 Sep 2011
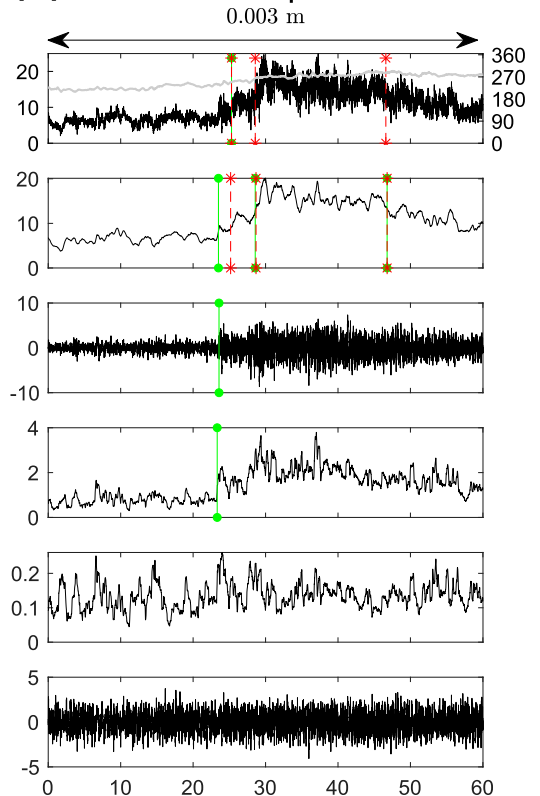

(e)

LI5: 4 Sep 2011
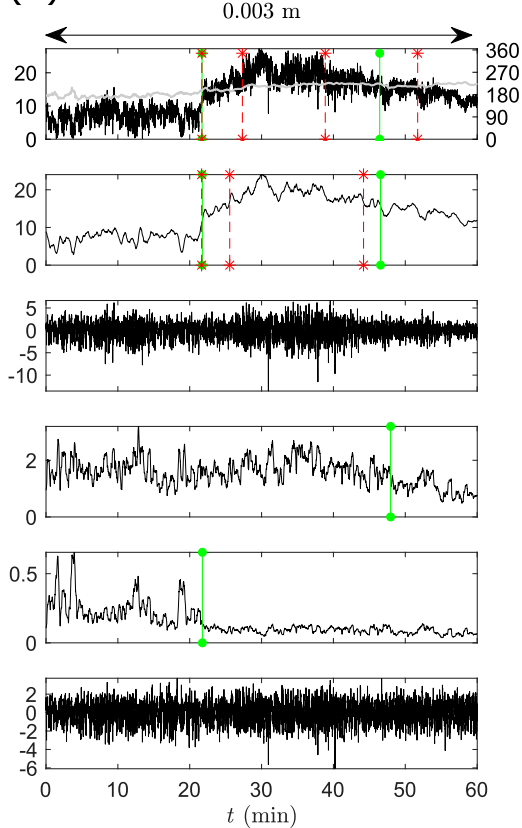

(c) LI3: 4 Sep 2011
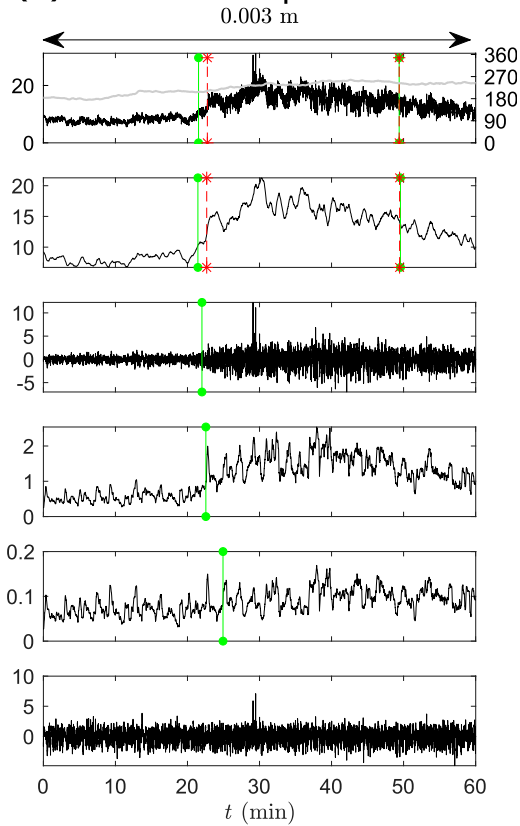

FIG. 7. As in Fig. 5, but for a thunderstorm event from Livorno captured with five anemometers. once again, shows that there seems not to be any apparent connection between those two parameters and the changepoint locations in either M or SD statistics.

Next, the LI event from 26 October 2012 (Figs. 6d-f) is particularly interesting because neither $U(t)$ nor $\bar{U}(t)$ from the LI4 anemometer (Fig. 6f) have an SD changepoint. However, the SD changepoints appear in $\sigma_{U}(t)$ and $I_{U}(t)$. This result suggests that, in rare cases, turbulent fluctuations during the thunderstorm passage might be difficult to detect (or even undetectable) in the instantaneous velocity records due to the high variability of the mean flow that governs $U(t)$ and therefore masks the changepoints in SD. Also, apart from many other events analyzed in this paper, this anemometer record is characterized by relatively constant $\alpha(t)$ and, consequently, no change of $z_{0}$ occurred throughout the event.

The LI event from 4 September 2011 is the last event analyzed in this subsection (Fig. 7). The event is unusual 
because while the $U(t)$ records from all anemometers are visually very similar, the changepoint method shows that the statistical properties are different among the records. Although the same model settings are used in all velocity records in Fig. 7, the number and location of changepoints are not the same. Therefore, the analyzed thunderstorm outflow was highly localized because statistical properties are different from one location in the outflow to another. Similar to Fig. 6, this event was also characterized by the constant value of $z_{0}$ throughout the record.

\section{2) The United States}

Figure 8 shows the abrupt changes in several velocity records from the United States. In comparison to the events from Europe that are usually associated with single- and multicell thunderstorm clouds (Burlando et al. 2017, 2018), the PE, SE, and LU (21 May 2008 and 4 June 2009) events were supercells with rear flank downdrafts, misovortices, or mesoscale convective systems such as bow echoes and mesoscale convective complexes (Holmes et al. 2008; Lombardo et al. 2014; Gunter and Schroeder 2015; Gunter et al. 2017). Further, the comparison of PE and SY events against the rest of LU records in Fig. 8 is also appealing due to the discrepancies in the length of the velocity records-the former is about 6 times longer. Despite this difference in length, the dominant thunderstorm velocity peaks are identified in all $U(t)$ records using the $\mathrm{M}$ method. In some cases (e.g., Figs. 8a,d,e,f), wind fluctuations extend beyond the first peak, and the SD method accordingly separates the larger portion from the entire velocity record. The $\mathrm{M}$ changepoints in $\bar{U}(t)$ and $U(t)$ always occur at the same position in the records. In the PE event, a secondary circulation on the leading edge of the outflow contributed to the multiple peaks in the velocity record (Gunter et al. 2017). This result, once again, demonstrates that the abrupt changes in the mean velocity are driven by the large-scale flow structures in thunderstorm winds. While the interpretation of changepoints in the rest of decomposed records in Fig. 8 is more challenging than the explanation of changepoints in $\bar{U}(t)$, we notice the inconsistency in the location of changepoints in $I_{U}(t)$. While in some cases $I_{U}(t)$ is a stationary process in terms of SD (Figs. 8b,f), in other cases, there are sharp changes of SD in the $I_{U}(t)$ records (Figs. 8c,d,e). These changepoints cannot be associated with the abrupt changes of $z_{0}$ for different values of $\alpha$ because the sites are characterized by the homogeneous and isotropic roughness. Because the anemometer heights were also comparable, it is not clear if this factor could be the governing contributor for the location and number of changepoints in this case.

Last, we briefly analyze the LU event from 4 June 2002 that was measured with multiple anemometers.
Figure 9 shows the changepoints in 6 out of 12 velocity records from this event. All measurements were constrained below the heights of $15 \mathrm{~m}$, where the influence of surface roughness is deemed to be significant. The $U(t)$ records show a high degree of similarity in terms of the number and locations of changepoints. In all cases, these 30-min records are characterized by two $\mathrm{M}$ changepoints (the thunderstorm peak) and a maximum of one SD changepoint. The SD changepoints, in all cases, separate the thunderstorm wind segment from the winds after the thunderstorm. The changepoint locations are consistent in all $\bar{U}(t)$ records and the absence of changepoints is noticed in the records of $I_{U}(t)$ and $\tilde{U}^{\prime}(t)$.

\section{3) Australia}

The velocity records from Australia are only analyzed in terms of $U(t)$ due to the low sampling frequency of obtained data (Table 1). All $U(t)$ records from BR are shown in Fig. 10. The similarity between time histories of $U(t)$ at 58 and $104 \mathrm{~m} \mathrm{AGL} \mathrm{(Figs.} \mathrm{10a,b)} \mathrm{is} \mathrm{higher} \mathrm{re-}$ garding the location and number of changepoints than between either of the two records and 10-m data from the nearby mast (Fig. 10c). However, because the duration of these velocity records is also different, the similarities are discussed only in terms of the central 10 -min velocity peak. The analysis of numerous records whose duration is $\geq 60$-min has shown that 10-min records are not sufficiently long to accurately represent the entire transient nature of thunderstorm winds and their separation from the background winds before and after the event. We again observe that the SD portion is longer than the $\mathrm{M}$ segment that envelops the central velocity peak.

\section{b. Spectral analysis}

The turbulence spectra obtained from all $\tilde{U}^{\prime}(t)$ records with $f_{s} \geq 1 \mathrm{~Hz}$ are shown in Fig. 11. The LU thunderstorm of 4 June 2002 is the only U.S. event that entirely entered into this analysis due to the anemometer response issues reported in the other U.S. events (Lombardo et al. 2014; Gunter et al. 2017). The power spectral density (PSD) analysis of the Lubbock events from Lombardo et al. (2014) is limited to the frequency range $0.04-1 \mathrm{~Hz}$ due to the internal anemometer sampling procedures and anemometer response issues. Also, mechanical filtering and second-order anemometer response characteristics resulted in unreliable energy spectra between 0.4 and $5.4 \mathrm{~Hz}$ for the PE and SY events (Gunter et al. 2017). Propeller-vane anemometers mechanically filter wind speed in proportion to the anemometer's distance constant due to the propeller inertia. The distance constant of an anemometer is the length of airflow past the sensor required to cause it to respond to $63.2 \%$ of the increasing step function change in wind speed. 

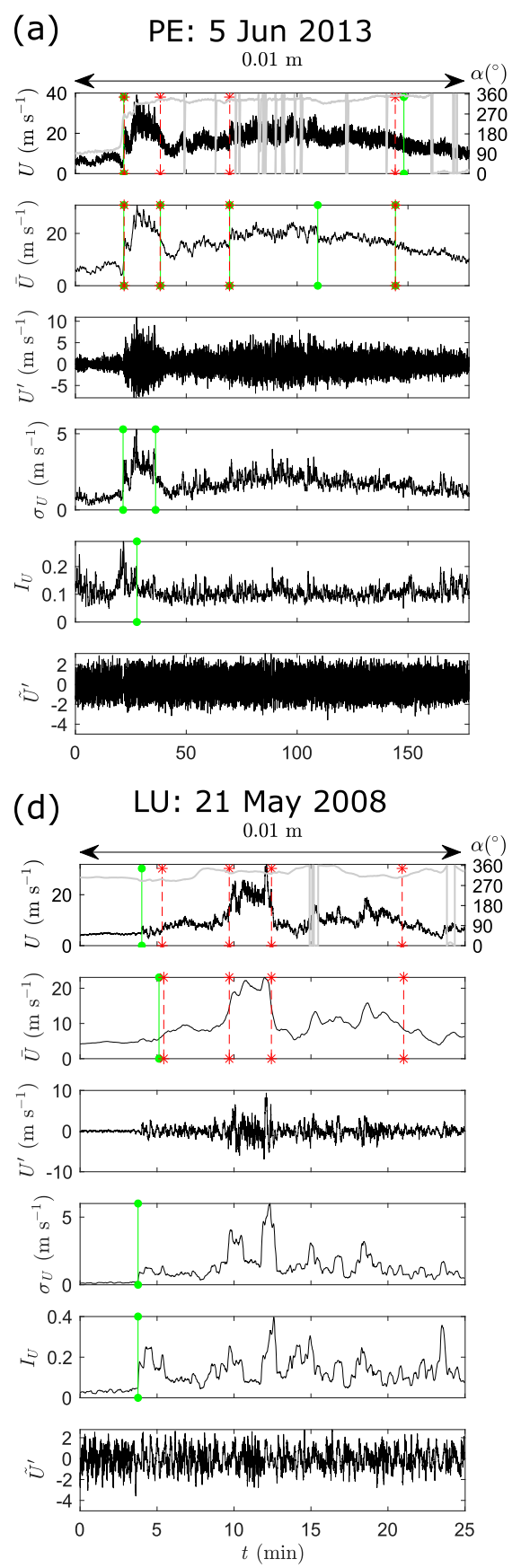

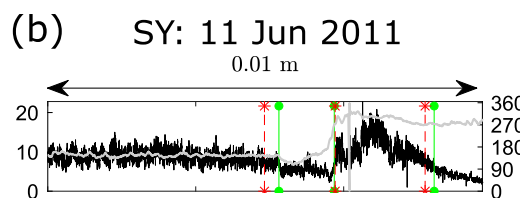

(c) LU: 24 Aug 2007
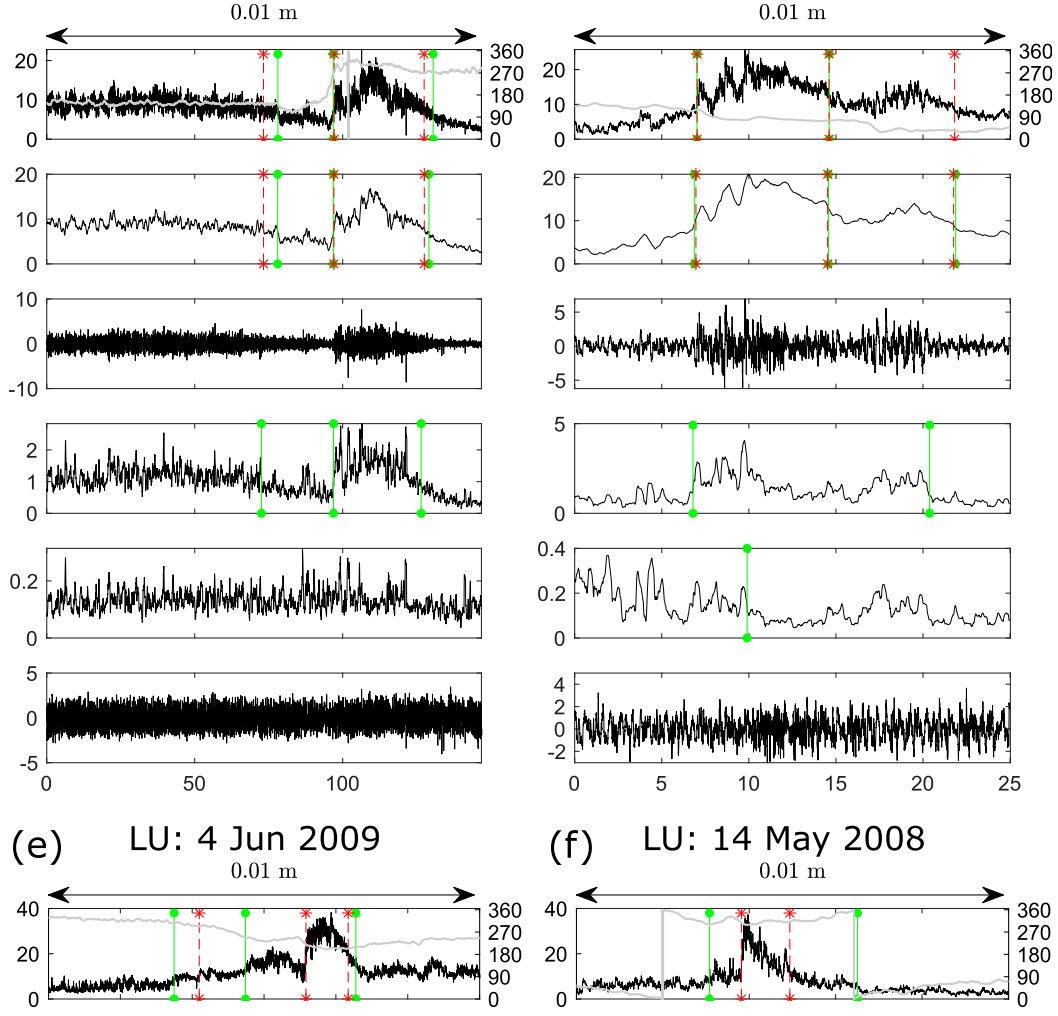

(f) LU: 14 May 2008
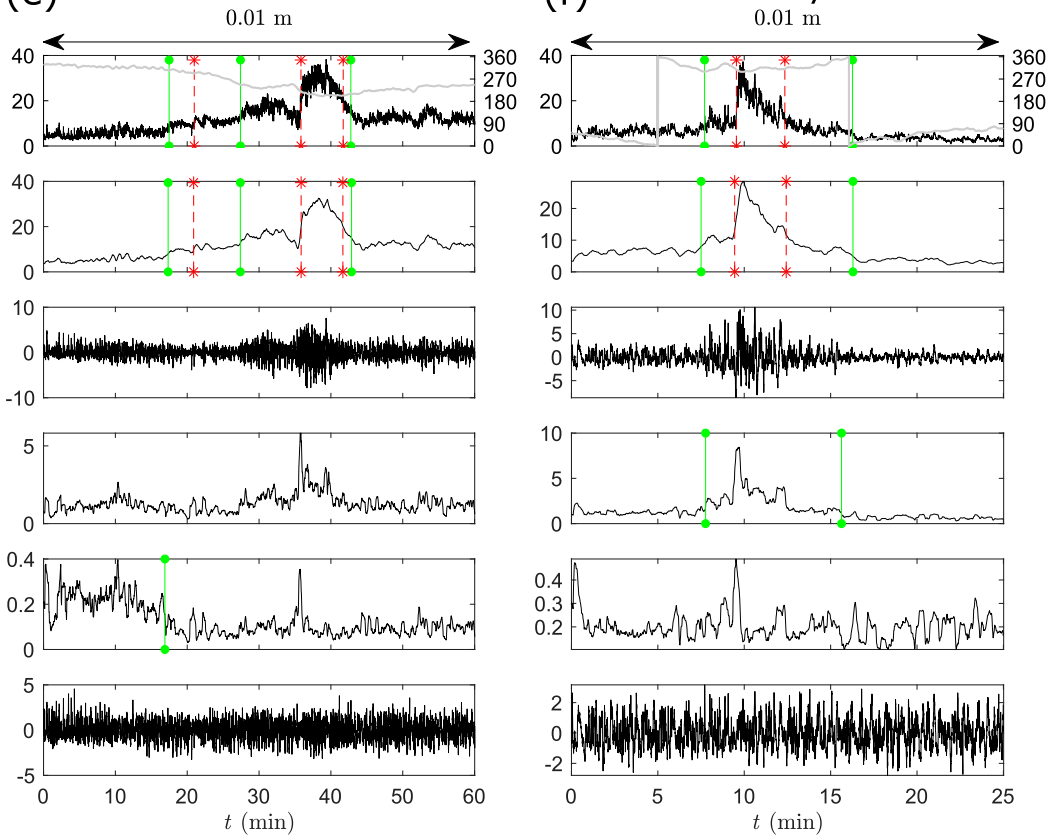
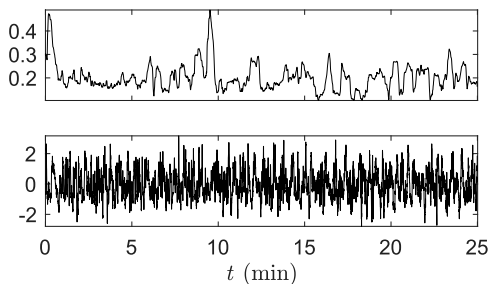

FIG. 8. As in Fig. 5, but for several thunderstorm events from the United States.

Gunter et al. (2017) and Schroeder and Smith (2003) showed that the distance constant of $2.7 \mathrm{~m}$ diminishes a wind gust with a wavelength of $30 \mathrm{~m}$ by $13 \%$, and a wind gust of $17 \mathrm{~m}$ wavelength by approximately $71 \%$. That is, the anemometer mechanically filters the amplitudes of short wavelength gusts.

These unreliable segments of PSDs are not included in Fig. 11. Here, the PSDs are evaluated using the Welch
(1967) method of modified periodograms with a Hamming window of $2^{8}$ velocity readings. A $50 \%$ overlap between adjacent windows was applied. While all thunderstorm records from Europe are characterized by a $-5 / 3$ slope of PSD in the inertial subrange (Fig. 11), the steeper slope of PSD is found in the U.S. events. This deviation from the typical ABL spectra was also reported in Holmes et al. (2008) and Lombardo et al. (2014). The larger slope in the 


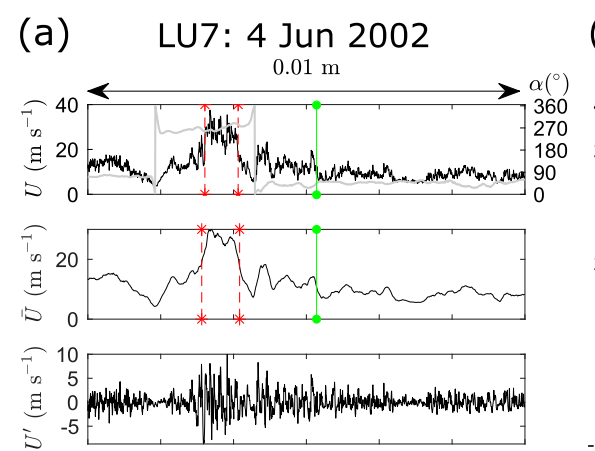

(b) LU6: 4 Jun 2002
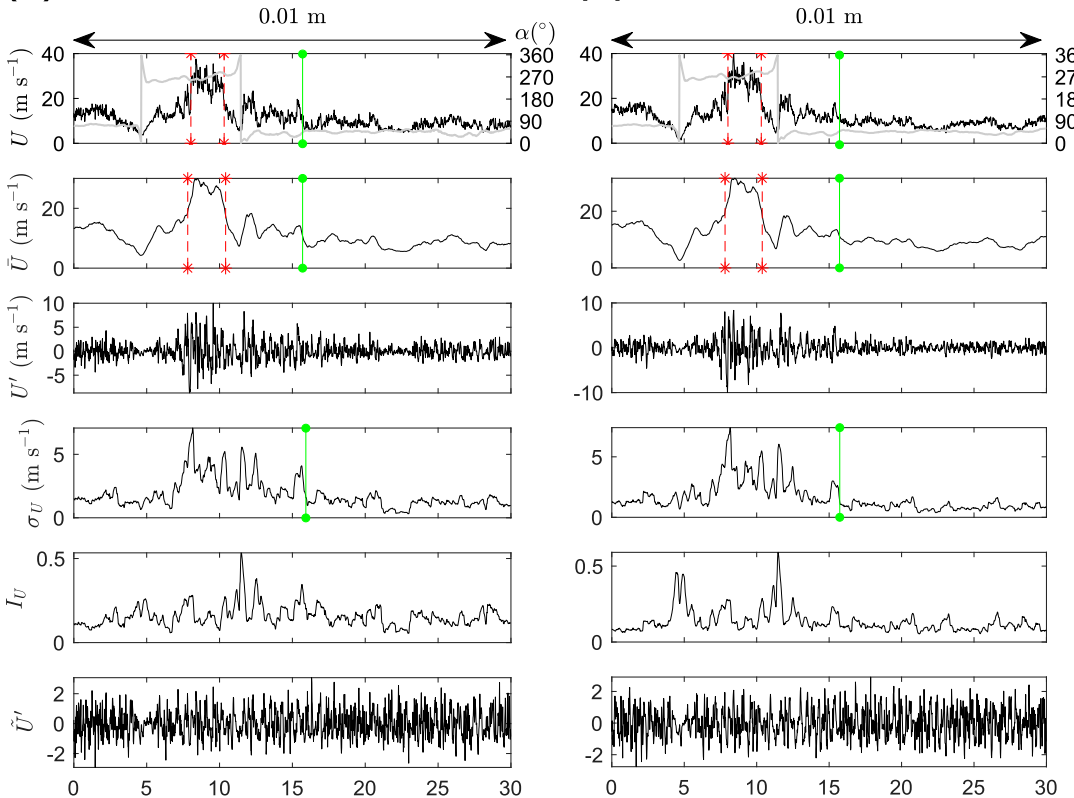

(d)

LU4: 4 Jun 2002
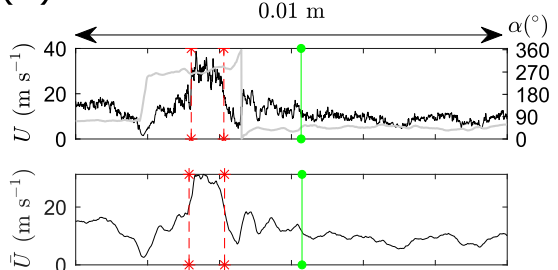

I 10

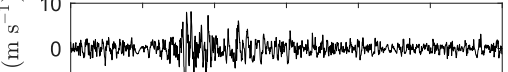

$\lesssim-10$

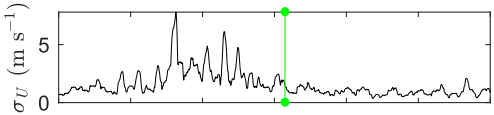

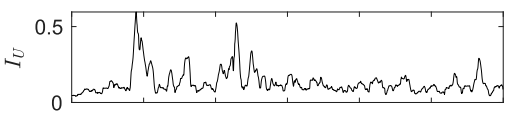

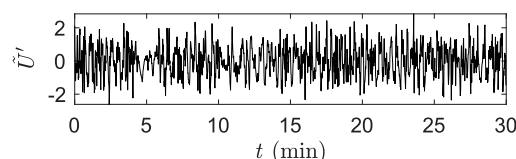

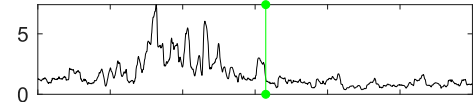
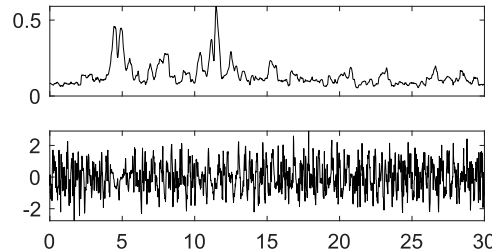

(e)

LU3: 4 Jun 2002
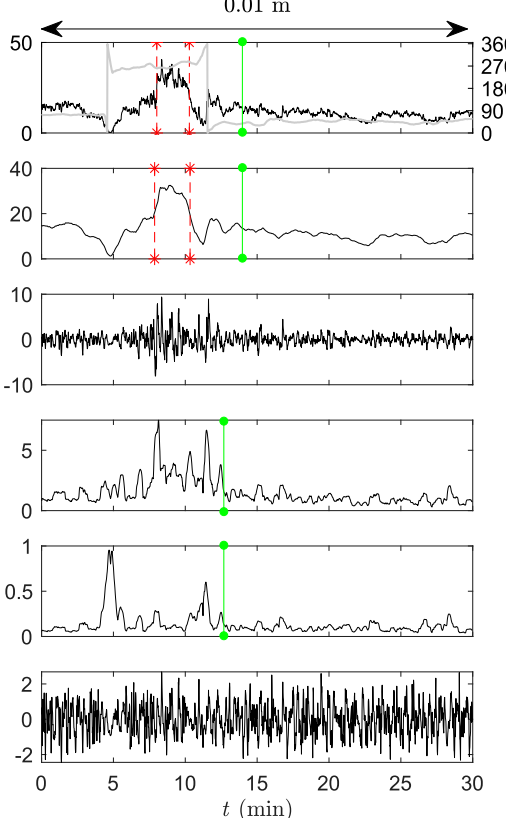

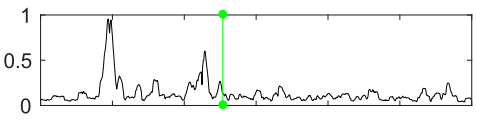

(c) LU5: 4 Jun 2002
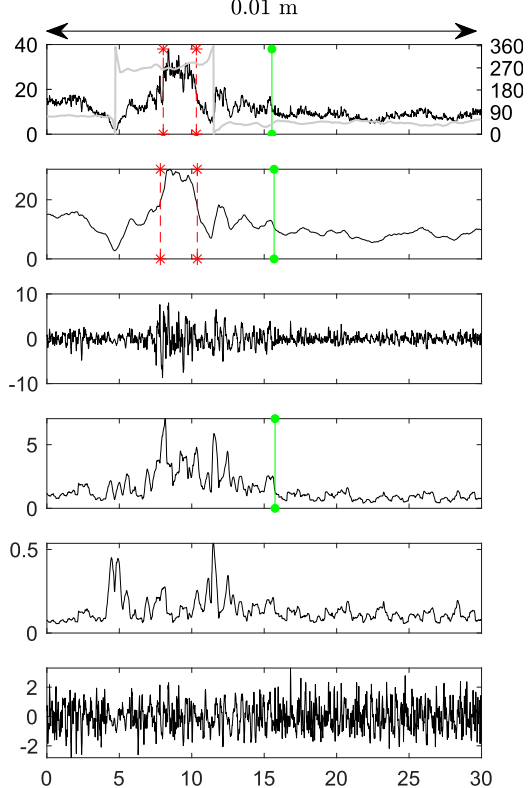

(f) LU1: 4 Jun 2002
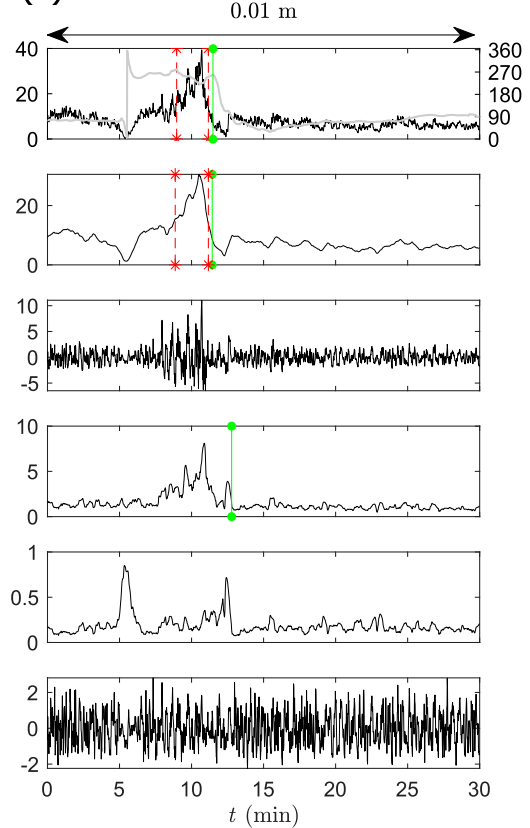

FIG. 9. As in Fig. 5, but for a thunderstorm event from Lubbock captured with 12 anemometers (only 6 records shown).

events from Lombardo et al. (2014) is found at the frequencies higher than approximately $0.375 \mathrm{~Hz}$. Also, there seems to be a well-established peak centered around $0.8 \mathrm{~Hz}$ in all $\tilde{U}^{\prime}(t)$ records from the LU event of 4 June 2002 (not explicitly shown). The peak origin and the deviation of PSD slope from the reference slope in the U.S. data are not fully understood at this point. One possible explanation often presented in the literature is the applicability of
Eq. (12) and the 30-s averaging window in separating low- from high-frequency fluctuations (Holmes et al. 2008; Lombardo et al. 2014). This issue was thoroughly addressed in Solari et al. (2015). The peak and the steeper slope could also be caused by an anemometer issue or insufficient data quality that stayed unknown to the authors.

The PSD flattening for the European events in the highest frequency domain was also reported in Burlando 

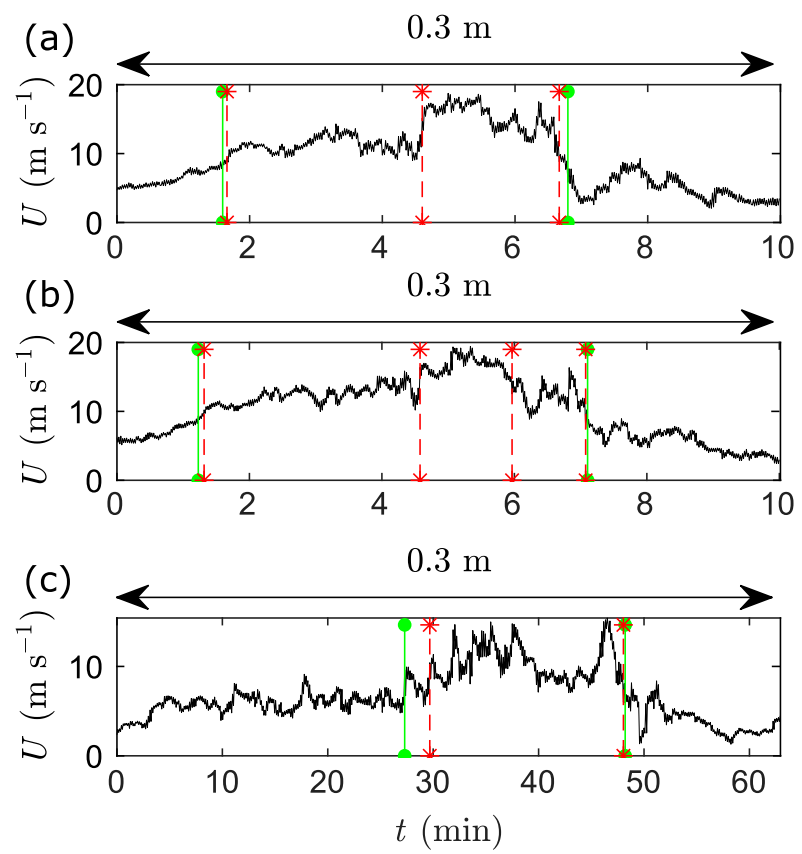

FIG. 10. Changepoints in the $\mathrm{M}$ and SD statistics in the $U(t)$ records from the Brisbane event in Australia. (a)-(c) Anemometers BR1-3, respectively.

et al. (2017) and a likely cause is spectral aliasing and anemometer noise. For example, this feature is not observed in the PSDs from HY (Finland) and LS (Italy) events (not explicitly shown Fig. 11). However, it should also be noted that the spectra and other results discussed herein are not necessarily the "typical" representative of thunderstorm velocity records in these regions due to the limited number of cases that are considered in this research.

The segmentation methodology also enables the PSD analysis of specific segments in the $U(t)$ records in which the $\mathrm{M}$ and SD changepoints occurred at the same or similar times (e.g., HY in Fig. 5a, LS of 5 October 2011 in Fig. 5c, LI3 of 26 October 2012 in Fig. 6e). Figure 12 shows the results of this analysis on the example of HY data. Since the PSDs in Fig. 12 are not normalized; their values are proportional to the velocity fluctuations in the represented segment. The PSD of thunderstorm peaks (black line) is associated with the highest fluctuations and more turbulent energy than the rest of the velocity record. At a given frequency, the separation between PSD of the thunderstorm peak and the PSDs of the winds before (dark gray) and after (light gray) the peak is proportional to the fluctuation differences in the corresponding velocity segments. Analyzing multiple anemometer records, we noticed that there is no clear distinction between fluctuations in the winds before and after the thunderstorm from one event to another (not

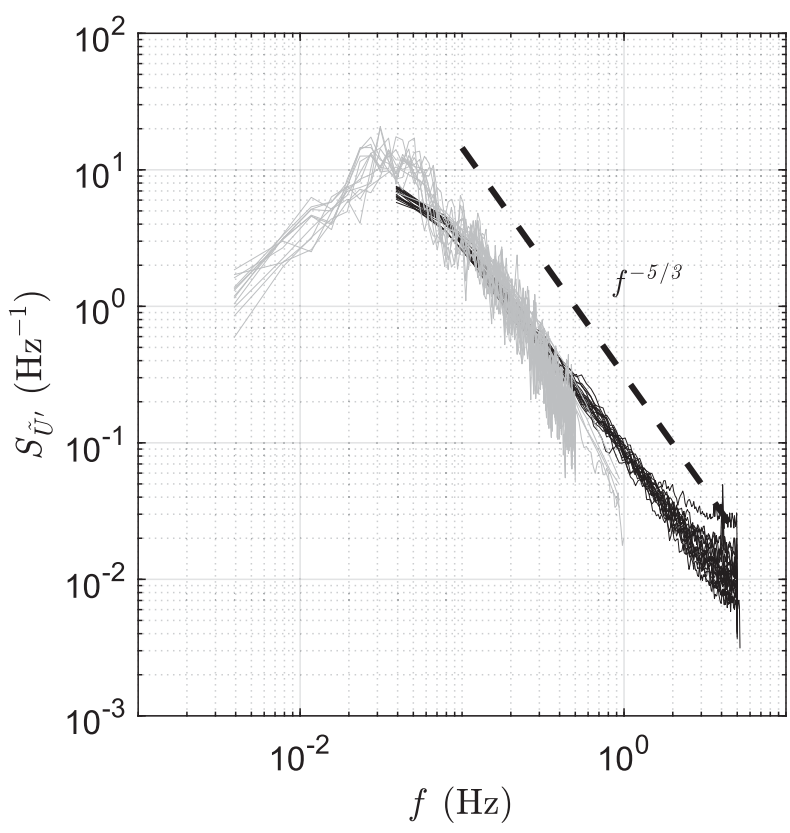

FIG. 11. Power spectral density (PSD) functions of all $\tilde{U}^{\prime}(t)$ records with $f_{s} \geq 1 \mathrm{~Hz}$ from the United States (gray) and Europe (black). The black dashed line is the $-5 / 3$ slope.

shown in Fig. 12). In some cases, the velocity fluctuations before the thunderstorm peak are more pronounced than in the winds after the peak, and sometimes the reverse. These results cannot be a priori attributed to surface roughness changes due to the constant wind direction in some of the investigated cases.

\section{c. Model applications}

The proposed segmentation method is objective and accurate at separating the so-called intermediate wind events from the thunderstorm winds (De Gaetano et al. 2014). The intermediate winds are defined as a stationary and non-Gaussian wind, whereas the thunderstorm winds are nonstationary and non-Gaussian. As discussed in the Introduction, the De Gaetano's methodology distinguishes thunderstorm and intermediate winds from the ABL winds using the 10-min and 1-h values of various statistical parameters averaged over 1-s and 1-min intervals, respectively. However, further separation between the thunderstorm and intermediate winds is afterward manual and depends on visual examination of the velocity records. Figure 13 shows two intermediate wind records, both from La Spezia, Italy (De Gaetano et al. 2014). These records are similar to thunderstorm winds in terms of gust factors and higher-order statistics (De Gaetano et al. 2014; Jubayer et al. 2019), but visually the time histories are profoundly different from the thunderstorm winds that occurred in La Spezia (Figs. 5c-e). The intermediate winds-while evidently 

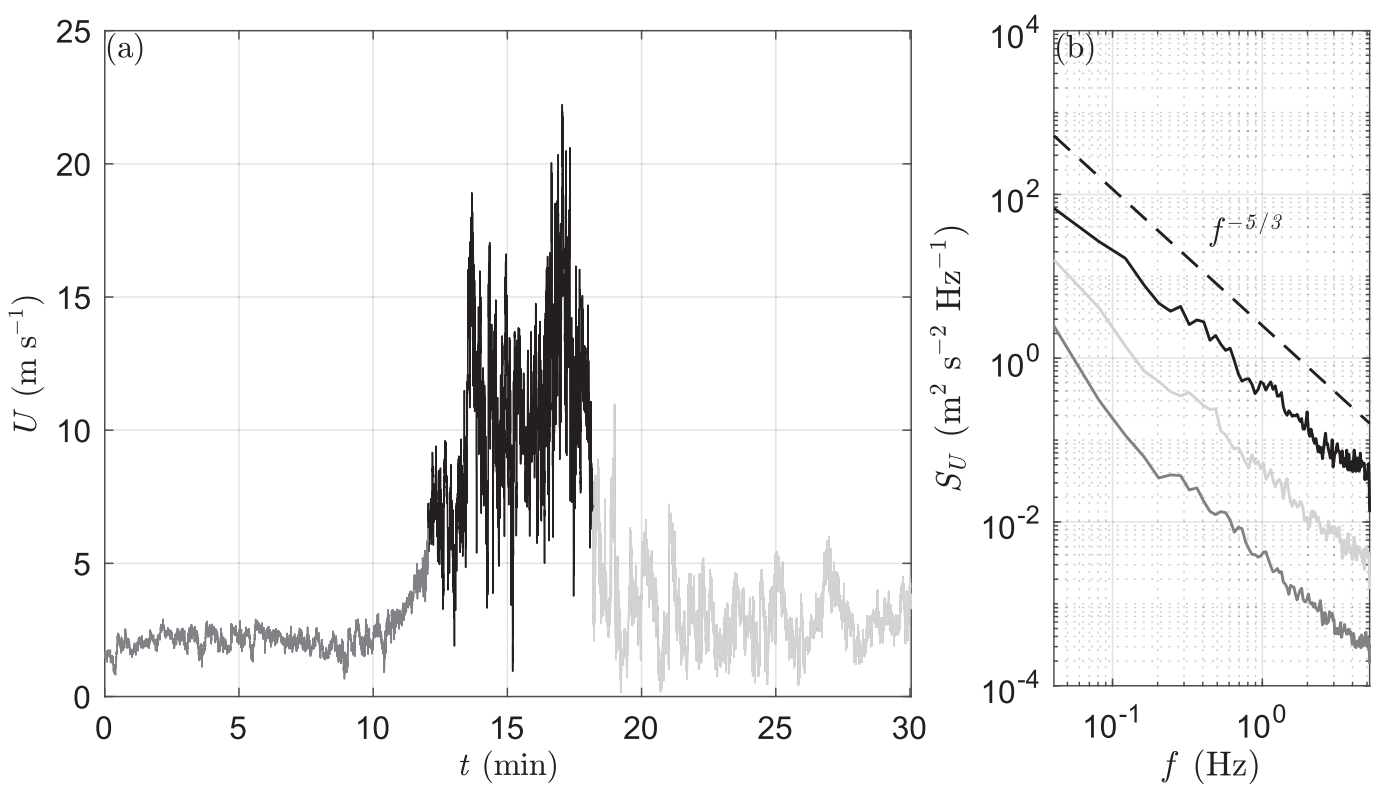

FIG. 12. (a) Three segments in the HY velocity record: (a) winds before thunderstorm (dark gray), (b) thunderstorm peak (black), and (c) winds after the thunderstorm (light gray). (b) PSD of the thunderstorm segment (black) and the winds prior to and after the thunderstorm segment (dark gray and light gray, respectively). The black dashed line is the $-5 / 3$ slope.

different from thunderstorms-remained undistinguishable from the thunderstorm winds in the De Gaetano's wind classification method. However, the application of the proposed segmentation methodology to the intermediate winds in Fig. 13 shows a complete absence of changepoints in both M and SD statistics. Therefore, the absence of changepoints in these types of winds can be implemented to the De Gaetano's procedure to separate the thunderstorm from intermediate winds. The methodology is objective and certainly faster than the subjective visual interpretation that is currently used. It is equally important to emphasize that the penalty constant $\gamma$ is set to the values of 20000 and 10000 for the M and SD statistics, respectively, which were also the values used to detect multiple changepoints in the thunderstorm wind records from the same anemometer stations.

We also compare our methodology against the segmentation method proposed in Lombardo et al. (2014). Both methods almost identically identified the beginning of the thunderstorm segment (Fig. 14), but our method extends the duration of the first peak in terms of both $\mathrm{M}$ and SD statistics in comparison to the Lombardo et al. (2014) methodology. Also, the existence of the second thunderstorm peak is identified in the $M$ approach, whereas this segment is absent in Lombardo et al. (2014) and SD statistics. While the Lombardo's method inspects the stationarity of data by performing the reverse arrangement and run tests on data segments, the current methodology recursively minimizes the residual error of segments in terms of the given statistics (M or SD), as described in section $2 \mathrm{~b}$. Without an attempt to determine which methodology is "better" at detecting changepoints, we notice that the method
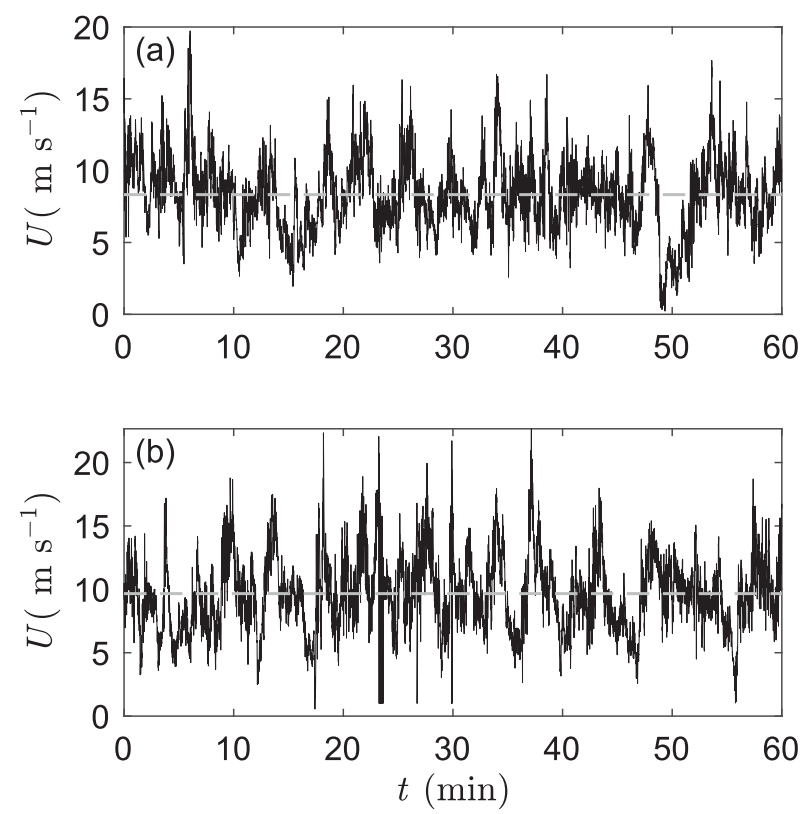

FIG. 13. Application of the proposed segmentation method to intermediate winds from De Gaetano et al. (2014). The dashed horizontal lines indicate the absence of changepoints in both $\mathrm{M}$ and SD statistics. 


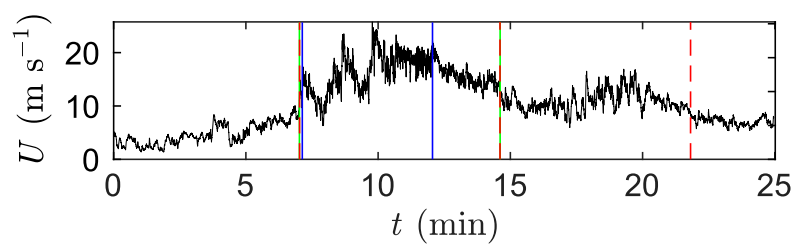

FIG. 14. The LU event of 24 Aug 2007 [see Fig. 8c from Lombardo et al. (2014)]. The blue vertical lines show the changepoints detected using the segmentation method in Lombardo et al. (2014). The green and red lines are the SD and M changepoints, respectively, detected using the segmentation method presented in this study.

presented herein is robust because the number of changepoints depends only on $\gamma$. Fewer or more changepoints can be detected by increasing or decreasing $\gamma$, respectively. More changepoints being detected in Fig. 14 also indicates that the proposed method can identify finer-scale features in the velocity records. Last, the proposed method in this article is tested for a broader range of thunderstorm winds, including different record durations, geographic origin of the records, and sampling frequencies.

\section{d. Model sensitivity}

The introduced model for the detection of changepoints in thunderstorm wind records is robust because the number of changepoints depends only on the value of $\gamma$ in Eq. (1). The larger $\gamma$ results in fewer changepoints. Therefore, the first objective of this research was to determine the value of $\gamma$ that would separate velocity records into physically consistent segments. This step requires users to be knowledgeable about thunderstorm wind dynamics and velocity signatures. Yet another goal was to use the same (or at least similar) value of $\gamma$ for the analysis of most velocity records. The second objective was imposed to make the model robust and consistent for a wide range of thunderstorm winds.

Figure 15 shows that the proper segmentation of the GE event (30 September 2012; Fig. 5b) is obtained for $\gamma_{M} \cong 6000$ (subscript "M" stands for the mean cost function) and the further increase of $\gamma_{M}$ does not introduce additional changepoints. However, the model is sensitive to $\gamma_{\mathrm{M}}<5000$ and a different number of changepoints is found depending on the exact value of this parameter. This relationship is more subtle in the case of high-frequency data, such as the LU event from 4 June 2009 (Fig. 15), because these measurements can reveal more finescale structures in the flow. In this event, the number of changepoints decreases from 65 to 8 for the values of $\gamma_{M}$ ranging between 20000 and 1000 .

The following analysis further investigates the relationship between $\gamma_{\mathrm{M}}$ and $f_{s}$ in Figs. 16 and 17. Here,

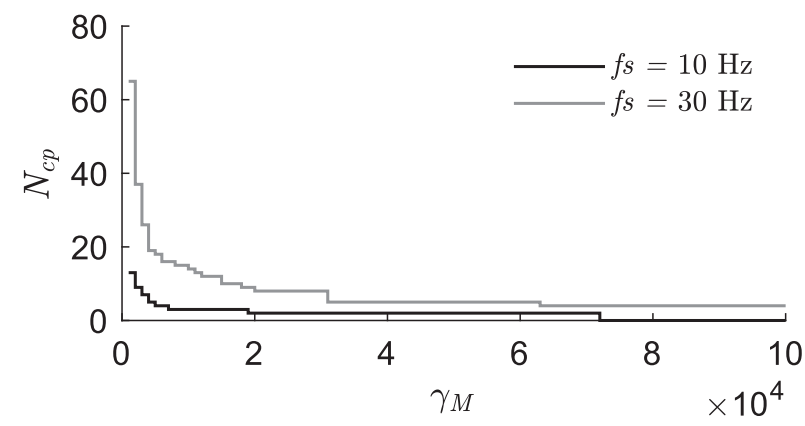

FIG. 15. The number of detected changepoints $N_{\text {cp }}$ (as a function of $\gamma_{\mathrm{M}}$ for two different sampling frequencies. The analyzed 60-min records are GE (black line; 30 Sep 2012; 10-Hz data) and LU (gray line; 4 Jun 2009; 30-Hz data).

decimation is used to reduce artificially $f_{s}$ of measured data. The decimation method employs a lowpass Chebyshev type I infinite impulse response filter of order 8 (Parks and Burrus 1987) to reduce the signal bandwidth and guard against aliasing (Jackson 1996). This analysis demonstrates that, in order to preserve the same number and location of changepoints in the decimated velocity records, $\gamma_{M}$ needs to decrease with reducing $f_{s}$. This relationship between $\gamma_{\mathrm{M}}$ and $f_{s}$ for the M cost function is linear and in the form:

$$
\gamma_{\mathrm{M}}=\gamma_{\mathrm{ref}} f_{s},
$$

where

$$
\gamma_{\mathrm{ref}}=\left.\gamma_{\mathrm{M}}\right|_{f_{s}=1 \mathrm{~Hz}} .
$$

Figure 18 shows the values of $\gamma_{M}$ and $\gamma_{\mathrm{SD}}$ (the subscript "SD" stands for the SD cost function) used in this study, as well as their functional dependency on $f_{s}$ and the record duration $\Delta T$. For example, all velocity records from Europe are characterized by $\gamma_{\mathrm{M}}=20000$ and $\gamma_{\mathrm{SD}}=$ 10000 (mostly 60-min records), while all LU (4 June 2002) data with $\Delta T=30 \mathrm{~min}$ have $\gamma_{\mathrm{M}}=8000$ and $\gamma_{\mathrm{SD}}=$ 1500. We further observe that a simple linear regression in the form $\gamma_{\mathrm{SD}}=0.23 \gamma_{\mathrm{M}}+3000$ is accurate at predicting $\gamma_{\mathrm{SD}}$ from $\gamma_{\mathrm{M}}$. Namely, this model correctly evaluates $86 \%$ of the variance in $\gamma_{\mathrm{SD}}$ values. Moreover, since the number and location of changepoints in a velocity record are unchanged for a wide range of $\gamma$ values, as previously demonstrated in Fig. 15, the proposed relationship is accurate for a broad range of $\gamma_{M}$ values. While the values of $\gamma$ alone do not have a physical meaning, this parameter governs the number and location of changepoints and, therefore, can be related to the time scales of different $M$ and SD flow field features. The penalty function $\gamma$ can be fine-tuned to recognize more small-scale structures in the outflow. 

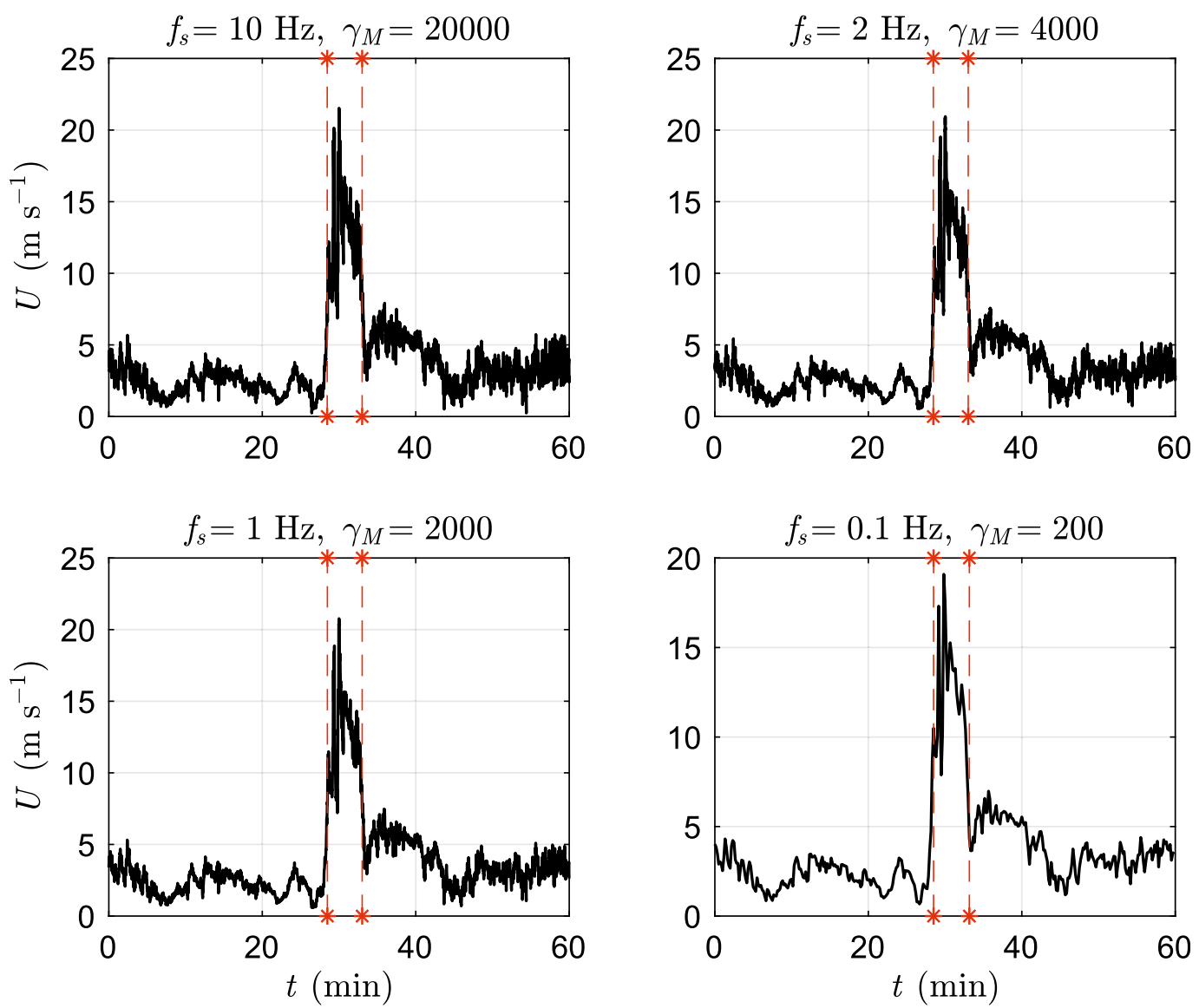

FIG. 16. The relationship between $\gamma_{\mathrm{M}}$ and $f_{s}$ for the $\mathrm{M}$ cost function demonstrated on the example of GE wind data (30 Sep 2012) with the acquisition frequency $f_{s}=10 \mathrm{~Hz}$.

\section{e. Transient characteristics of thunderstorm velocity records}

The duration of the thunderstorm wind peak and the ramp-up times are shown in Fig. 19. Here, the duration of thunderstorm velocity peak $\Delta T_{p}$ is defined as the length of $\mathrm{M}$ or SD segments that contain the dominant peak in the velocity record. The ramp-up time $\Delta T_{u p}$ is the interval between the first changepoint before the peak velocity and the time of the peak. This definition of ramp-up time is similar to the rise time often used in the analyses of turbulent velocity peaks in ABL winds (Hu et al. 2018).

The peak duration seems to be similar between the U.S. and European events (Fig. 19). In many cases, the SD segments of the thunderstorm peak are longer than the associated $\mathrm{M}$ segments. While this difference in segments duration is not always pronounced, Fig. 19a demonstrates that the fluctuations often precede and proceed the abrupt changes of $\mathrm{M}$. The duration of thunderstorm velocity peak is $2-5 \mathrm{~min}$ in approximately $60 \%$ of the analyzed records using the $M$ cost function (Fig. 19b), while the peak duration is $5-10 \mathrm{~min}$ in approximately $60 \%$ of the same records that are partitioned using the SD approach (Fig. 19c). Besides, there is not a velocity record in which the SD segment around the thunderstorm peak is shorter than $2 \mathrm{~min}$. The velocity records that are characterized by a single changepoint were not considered in this analysis because the peak duration cannot be evaluated in those cases.

The ramp-up times are below $2 \mathrm{~min}$ in approximately $60 \%$ of the analyzed velocity records using the M statistics (Fig. 19e). Similar to the duration times, the SD method isolates the longer ramp-up times than the $\mathrm{M}$ cost function (less than $10 \%$ of the records are characterized by the ramp-up time below $1 \mathrm{~min}$ ). Therefore, the thunderstorm winds seem to be more transient in terms of the abrupt changes of M than SD. Some events, such as the LU 4 June 2002, are characterized by a single changepoint in the SD statistic (Figs. 19a,d). Despite the low sampling frequency of the BR3 event from Australia and the WA event from the United States, these cases are still characterized by the similar peak duration and ramp-up times as the other events. This result shows that 

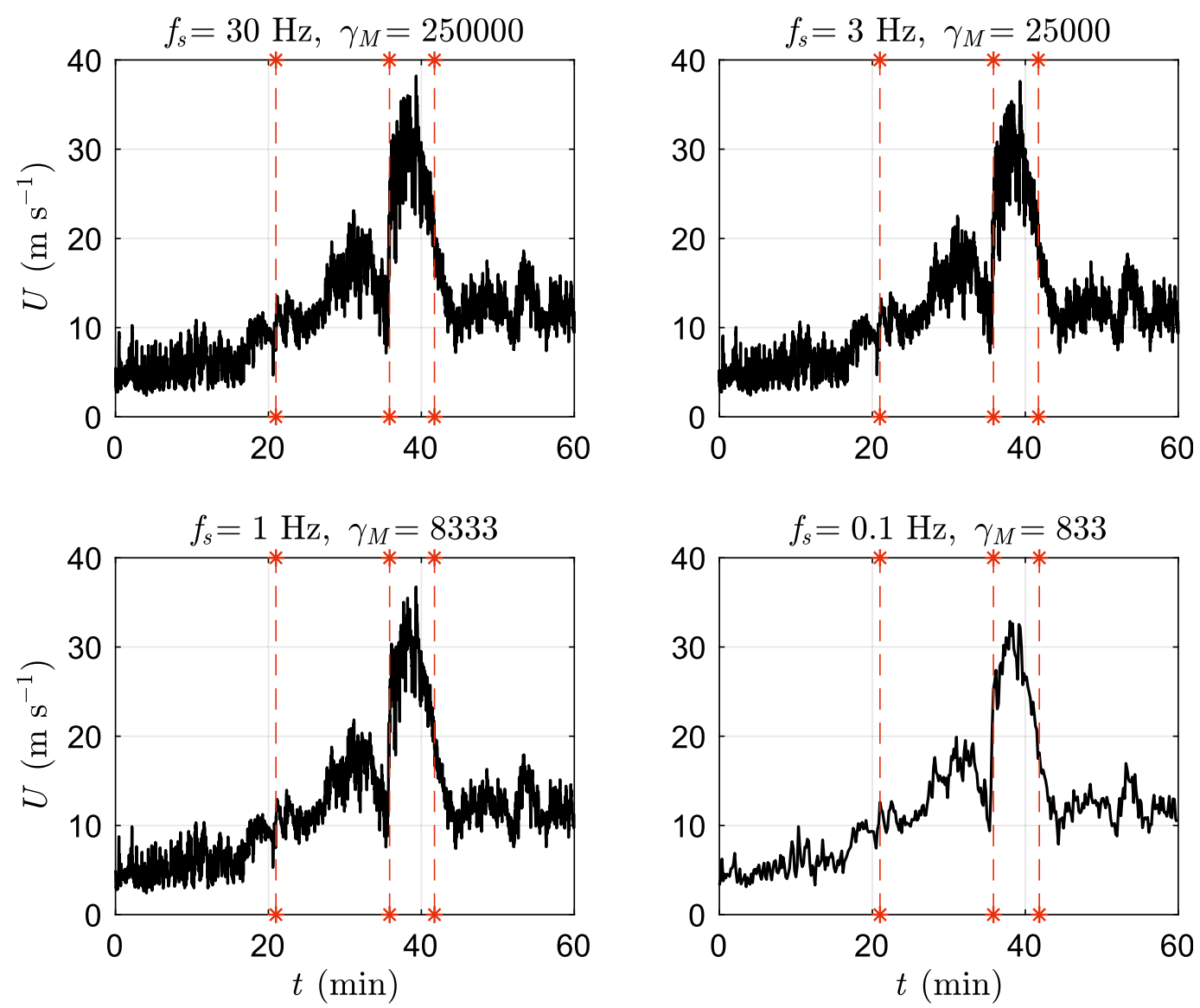

FIG. 17. As in Fig. 16, but for the LU (4 Jun 2009) data with the acquisition frequency of $f_{s}=30 \mathrm{~Hz}$.

the main transient features of thunderstorm records are noticeable even in the low-frequency data. Moreover, this analysis demonstrates that the proposed segmentation methodology is also applicable to low-frequency data.

Another parameter of importance in the analysis of thunderstorm winds is the velocity speedup during the thunderstorm wind episode. We quantify this speedup by defining a ratio of the maximum value of the slowly varying mean velocity during the thunderstorm segment $\hat{U}_{p}$ and mean wind speed prior to the thunderstorm $\bar{U}_{b}$ (the subscript " $b$ " stands for background):

$$
R_{m}=\frac{\hat{U}_{p}}{\bar{U}_{b}} .
$$

Similarly, we also define a ratio between the standard deviation of instantaneous velocity during the thunderstorm peak $\sigma_{p}$ and that during the background wind prior to thunderstorm $\sigma_{b}$ as

$$
R_{f}=\frac{\sigma_{p}}{\sigma_{b}} .
$$

The above ratios are only defined for the velocity records that have a clear distinction between the thunderstorm peak and the rest of the time series (i.e., more than one changepoint). The background segment is the interval between the beginning of the record and the first changepoint. For instance, the LU event of 4 June 2002 did not enter into this analysis due to the short duration of the velocity record and unclear existence of the background wind prior to the thunderstorm segment. The ratios in Eqs. (18) and (19) are similar to those defined by Solari et al. (2015) in their study of thunderstorm characteristics that are of importance in wind engineering. However, the ratios proposed herein directly quantify the abrupt changes in $\mathrm{M}$ and SD between the thunderstorm segment and the nonthunderstorm winds prior to the peak.

The maximum velocity during the thunderstorm peak in the events from Europe is typically 2-4 times larger than the mean wind speed before the event (Fig. 20). However, the HY event from Finland and the GE event from Italy are the exceptions because the ratio is much higher. The ratio $R_{f}$ is smaller than $R_{m}$ in the majority of analyzed records and, on average, $R_{m} \approx 1.65 R_{f}$. Therefore, 


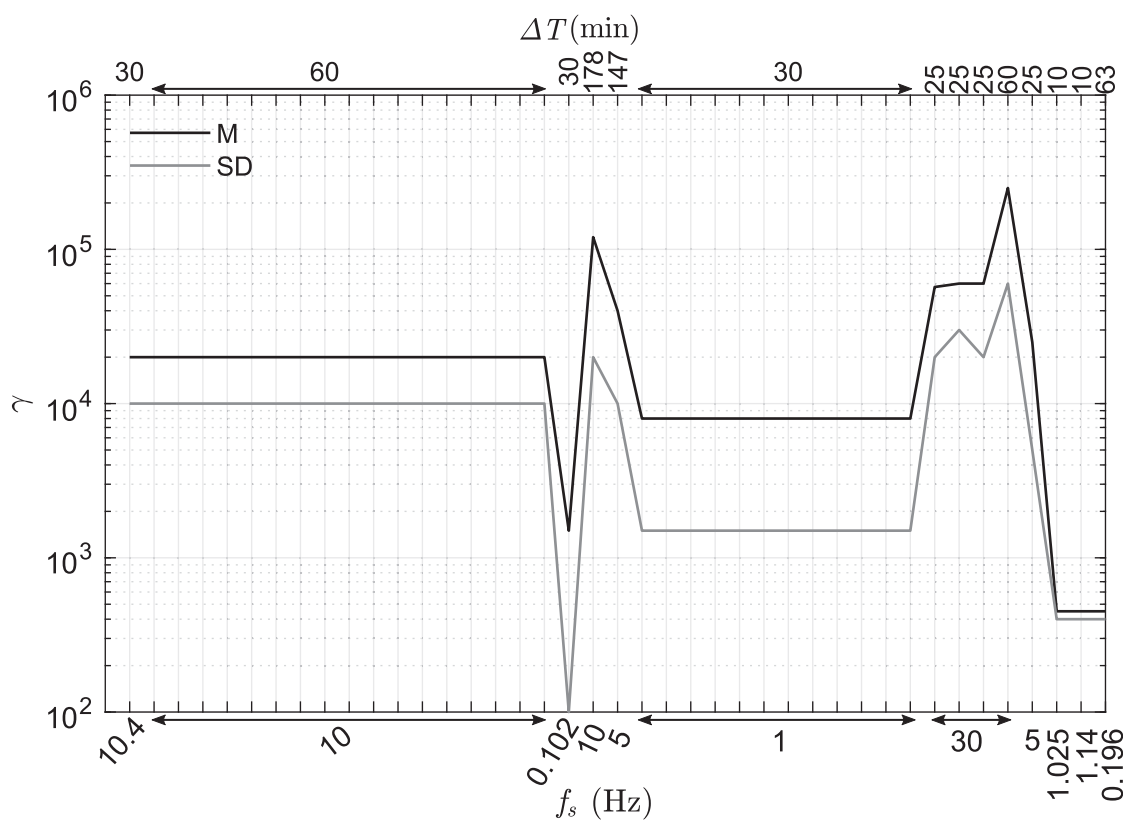

FIG. 18. The values of $\gamma$ used in this study plotted as the function of $f_{s}$ (bottom $x$ axis) and velocity record duration $\Delta T$ (top $x$ axis). The $y$ axis is logarithmic.

the abrupt changes associated with the largest scales of motion (represented through the mean and moving mean) are more pronounced than the changes in the smaller scales of motion (represented through velocity fluctuations). This result independently confirms (i.e., not through the length of isolated segments that was discussed previously) that the abrupt changes of $\mathrm{M}$ are more pronounced than the SD changes during the thunderstorm wind episodes. The U.S. events are characterized by slightly larger $R_{m}$ than European records. We did not observe any apparent relationship between $R_{m}$ or $R_{f}$ and $z_{0}$.

The reported ratios are also crucial for the proper physical reconstruction of thunderstorm winds in wind tunnels. Of particular importance are the wind simulators capable of simultaneously producing thunderstorm downbursts and background ABL winds (Romanic et al. 2019). Namely, the ratios impose the relative strength that the two simulated flows need to have in terms of mean velocity and turbulent fluctuations in order to satisfy the real atmospheric conditions. In most cases, the relative strength of the flows needs to be such that the peak velocity during the thunderstorm downburst is approximately 2-4 times higher than the mean wind speed in the background winds prior to the downburst.

\section{Conclusions}

This study investigated the transient characteristics of thunderstorm winds by using an objective method for the detection of changepoints in velocity records. The method seeks changepoints in anemometer records based on the statistical properties of different segments of time series (Lavielle 2005; Killick et al. 2012). The investigated wind statistics were the mean (M) and standard deviation (SD). We considered 41 velocity records from 19 thunderstorm wind events from Europe (Järvi et al. 2007; Solari et al. 2012), the United States (Fujita 1985; Orwig and Schroeder 2007; Lombardo et al. 2014; Gunter and Schroeder 2015), and Australia (Sherman 1987). The changepoint analysis was applied not only to the instantaneous velocity records but also to the decomposed time series in the form of slowly varying moving mean, moving standard deviation and moving turbulence intensity, as well as the residual turbulent fluctuations. The main conclusions of this study are briefly summarized below.

- The proposed methodology separated the central thunderstorm wind peak from the rest of the velocity records. The $\mathrm{M}$ and SD changepoints in the instantaneous velocity records coincide with the location of changepoints in the records of slowly varying velocity. This result demonstrated that the abrupt changes in the velocity records caused by the thunderstorm passage are predominantly associated with the changes in the mean (i.e., large scale) flow features. The SD segments that encompass the thunderstorm peak are usually longer than the M segments. 

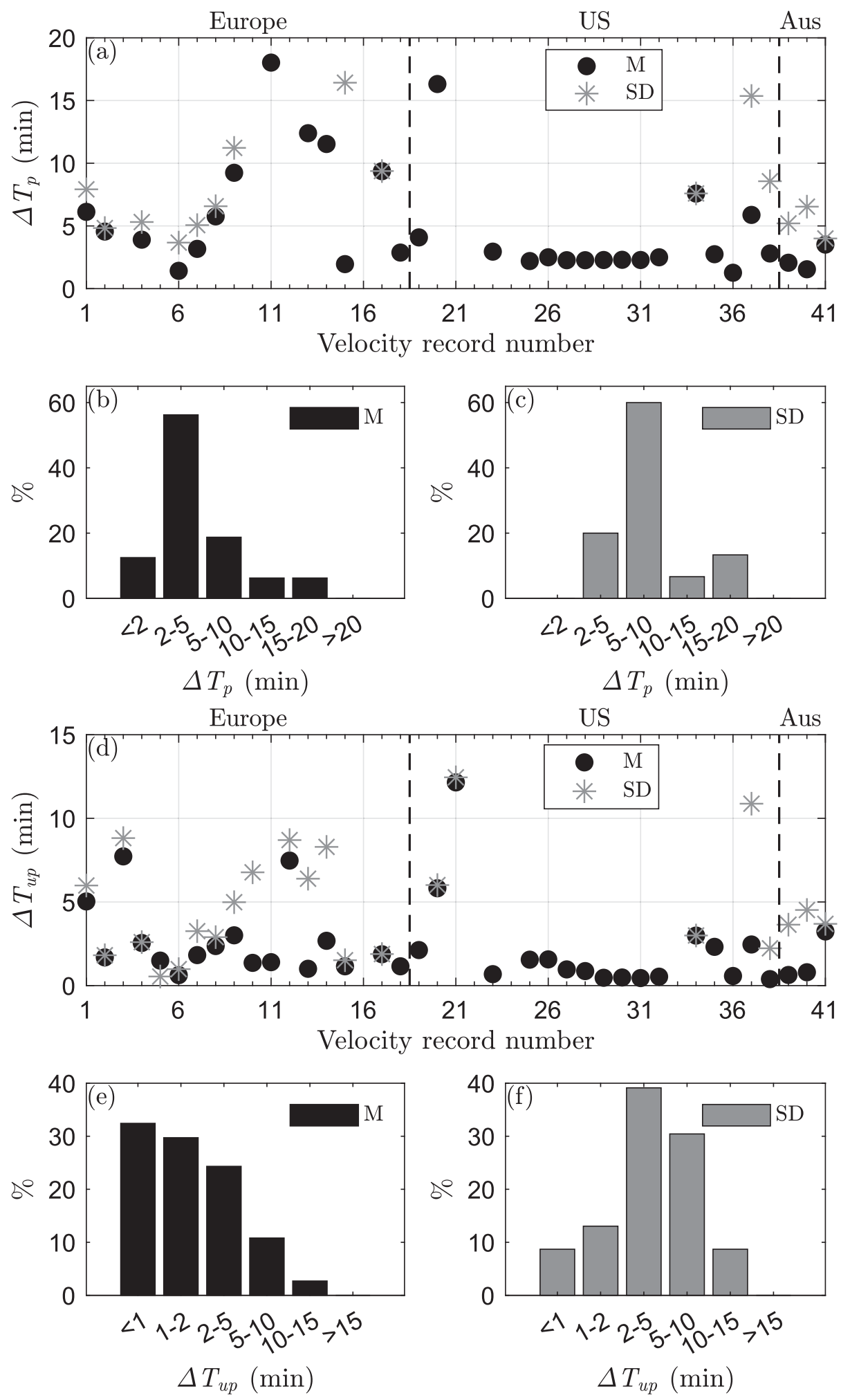

FIG. 19. (a) The duration of thunderstorm peak $\Delta T_{p}$ obtained using the $\mathrm{M}$ and SD cost functions. (b),(c) Associated histograms of $\Delta T_{p}$. (d)-(f) Similarly to the peak duration, these are the duration and histograms of the ramp-up times $\Delta T_{\text {up }}$. 


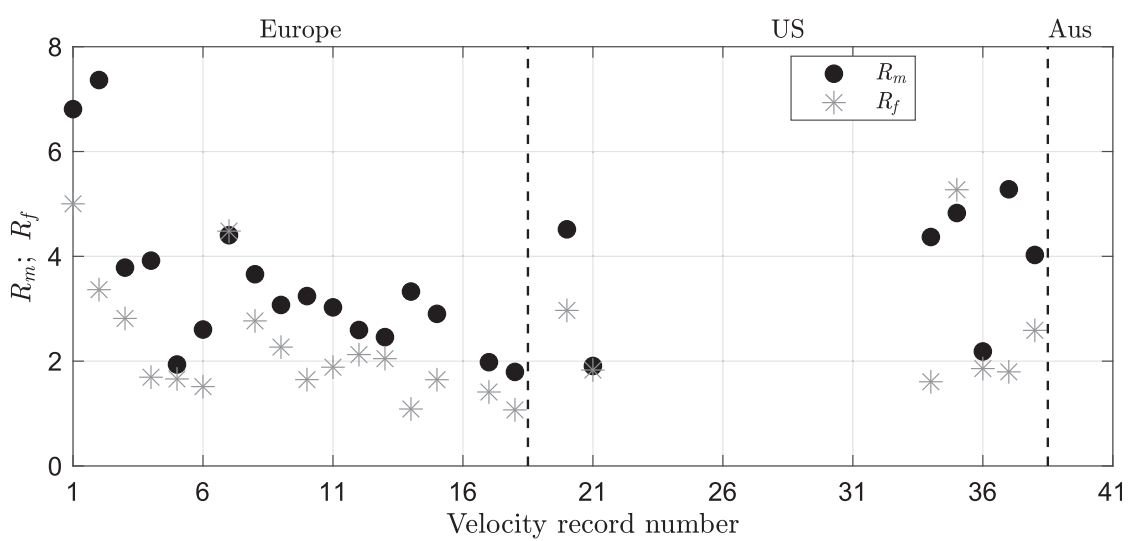

FIG. 20. The ratios of characteristic velocities and characteristic velocity fluctuations in the thunderstorm records.

- This systematic observation suggests that the changes in velocity fluctuations often precede and proceed the abrupt changes in the mean flow.

- This study did not find any methodical relationship between the time occurrence of changepoints in either $\mathrm{M}$ or SD statistics and the surface roughness changes associated with the shifts of wind direction during the thunderstorm wind episodes. It seems that the thunderstorm outflows might be too localized and transient to establish the flow equilibrium with the underlying surface. The absence of systematically detected changepoints in the records of slowly varying turbulence intensity and standard deviation for continually changing wind direction during some thunderstorm episodes partially supports the conclusion that the time evolution of thunderstorm winds is rapid to the point the flow field does not reach equilibrium with the terrain roughness. While similar results were also reported in Burlando et al. (2017), more research is needed on the dynamics and evolution of thunderstorm winds over the zones of abrupt roughness changes.

- The study further showed that the maximum velocity during the thunderstorm peak in the events from Europe is usually between 2 and 4 times larger than the mean wind speed before the event. This ratio seems to be higher for U.S. events, but the analyzed sample was too small to conclude this result firmly. Also, the U.S. events were more organized thunderstorm systems than the isolated thunderstorms in Europe, and this difference in thunderstorm morphology is probably an important factor that governed the above ratios. The duration of the thunderstorm velocity peak was $2-5 \mathrm{~min}$ in approximately $60 \%$ of the records segmented using the $M$ cost function and 5-10 min long when the records were partitioned using the SD statistic.
- Also, the ramp-up times of the mean flow were below $2 \mathrm{~min}$ in approximately $50 \%$ of the analyzed velocity records. Here, the ramp-up time was defined as the time interval between the velocity peak in the slowly varying velocity record and the first changepoint before the velocity peak. The ramp-up time was longer when the records were analyzed using the SD cost function.

- Last, this study provides the proper configuration of the proposed method for the detection of changepoints in velocity records. The values of threshold parameter $\gamma$ were derived for both M and SD cost functions, as well as different record durations. The functional dependency between $\gamma$ and the anemometer sampling frequency was also determined for the $\mathrm{M}$ and SD statistics. Practical applications of the method were demonstrated by objectively separating intermediate wind events from thunderstorm downbursts in the De Gaetano et al. (2014) methodology of wind type classification. Currently, their methodology differentiates between these two wind systems through visual observation of the records (i.e., an expert's opinion). Also, the performances of the proposed segmentation method were compared against the results of two similar methods employed by Lombardo et al. (2014).

Acknowledgments. The authors thank many researchers for kindly providing us the thunderstorm wind data analyzed in this study. Prof. Giovanni Solari from the University of Genoa, Italy, single handedly provided the data on all thunderstorm events from Italy. These anemometer data were recorded by the wind monitoring network of two European Union projects "Wind and Ports" and "Wind, Ports and Sea" funded by the "Italy France Maritime 2007-13" Cross-border Cooperation 
Programme. Prof. Leena Järvi from the University of Helsinki, Finland, generously shared with us the thunderstorm data from Finland. Prof. John Schroeder from Texas Tech University and Dr. Scott Gunter from Columbus State University kindly provided us with thunderstorm wind records from Pep, Texas, and Syracuse, Kansas. These anemometer data were collected within the scope of the project Severe Convective Outflow in Thunderstorms (SCOUT) and funded by the National Science Foundation Grant CMMI 1000160. The atmospheric boundary layer wind data in Fig. 1a are provided by the National Center for Atmospheric Research/Earth Observing Laboratory (NCAR/EOL) under the sponsorship of the National Science Foundation (https:// data.eol.ucar.edu/). Dr. Franklin T. Lombardo kindly shared with us the wind data from several thunderstorm wind events recorded at the Lubbock-Reese site in Texas. Some of the results in this paper are also published in the master's thesis of the second author that is available at https://ir.lib.uwo.ca/etd/5861/. The first author acknowledges the partial support of the European Research Council (ERC) under the European Union's Horizon 2020 research and innovation program (Grant 741273) for the project THUNDERR-Detection, simulation, modelling and loading of thunderstorm outflows to design wind-safer and cost-efficient structures-awarded with an Advanced Grant 2016. The authors also thank three reviewers whose comments significantly improved the quality of this work.

Data availability statement. Data analyzed in this study were a reanalysis of existing data, which are available at locations cited in the reference section.

\section{REFERENCES}

Basseville, M., and I. V. Nikiforov, 1993: Detection of Abrupt Changes: Theory and Application. Prentice Hall, 528 pp.

Bendat, J. S., and A. G. Piersol, 2010: Random Data: Analysis and Measurement Procedures. 4th ed. Wiley, $640 \mathrm{pp}$.

Brownlee, K. A., 1965: Statistical Theory and Methodology in Science and Engineering. 2nd ed. John Wiley \& Sons, 590 pp.

Burlando, M., D. Romanić, G. Solari, H. Hangan, and S. Zhang, 2017: Field data analysis and weather scenario of a downburst event in Livorno, Italy, on 1 October 2012. Mon. Wea. Rev., 145, 3507-3527, https://doi.org/10.1175/MWR-D-17-0018.1.

_ S. Zhang, and G. Solari, 2018: Monitoring, cataloguing, and weather scenarios of thunderstorm outflows in the northern Mediterranean. Nat. Hazards Earth Syst. Sci., 18, 2309-2330, https://doi.org/10.5194/nhess-18-2309-2018.

Changnon, S. A., 2001: Damaging thunderstorm activity in the United States. Bull. Amer. Meteor. Soc., 82, 597-608, https://doi.org/ 10.1175/1520-0477(2001)082<0597:DTAITU>2.3.CO;2.

Chen, J., and A. K. Gupta, 2012: Parametric Statistical Change Point Analysis: With Applications to Genetics, Medicine, and Finance. 2nd ed. Birkhäuser Basel, 273 pp.
Chen, L., and C. W. Letchford, 2004: A deterministic-stochastic hybrid model of downbursts and its impact on a cantilevered structure. Eng. Struct., 26, 619-629, https://doi.org/10.1016/ j.engstruct.2003.12.009.

_ and _ - 2006: Multi-scale correlation analyses of two lateral profiles of full-scale downburst wind speeds. J. Wind Eng. Ind. Aerodyn., 94, 675-696, https://doi.org/10.1016/j.jweia.2006.01.021.

Choi, E. C. C., and F. A. Hidayat, 2002: Gust factors for thunderstorm and non-thunderstorm winds. J. Wind Eng. Ind. Aerodyn., 90, 1683-1696, https://doi.org/10.1016/S0167-6105(02)00279-9.

Darkhovski, B. S., 1994: Nonparametric methods in change-point problems: A general approach and some concrete algorithms. ChangePoint Problems, Monogr. Series, Vol. 23, Institute of Mathematical Statistics, 99-107, https://projecteuclid.org/euclid.lnms/1215463117.

Davenport, A. G., 1961: The application of statistical concepts to the wind loading of structures. Proc. Inst. Civ. Eng., 19, 449472, https://doi.org/10.1680/IICEP.1961.11304.

De Gaetano, P., M. P. Repetto, T. Repetto, and G. Solari, 2014: Separation and classification of extreme wind events from anemometric records. J. Wind Eng. Ind. Aerodyn., 126, 132143, https://doi.org/10.1016/j.jweia.2014.01.006.

Droegemeier, K. K., and R. B. Wilhelmson, 1987: Numerical simulation of thunderstorm outflow dynamics. Part I: Outflow sensitivity experiments and turbulence dynamics. J. Atmos. Sci., 44, 1180-1210, https:// doi.org/10.1175/1520-0469(1987)044<1180:NSOTOD>2.0.CO;2.

ESDU, 1993: Computer program for wind speeds and turbulence properties: Flat or hill sites in terrain with roughness changes, version 2.1. Engineering Sciences Data Unit (ESDU), accessed 16 February 2017, https://www.esdu.com/cgi-bin/ps.pl? sess $=$ unlicensed_1200715025625fnt\& $\mathrm{t}=$ doc\&p=esdu_01008c.

Fujita, T. T., 1985: The downburst: Microburst and macroburst. Satellite and Mesometeorology Research Project (SMRP) Research Paper 210, Dept. of Geophysical Sciences, University of Chicago, NTIS PB-148880, 136 pp.

Goff, R. C., 1976: Vertical structure of thunderstorm outflows. Mon. Wea. Rev., 104, 1429-1440, https://doi.org/10.1175/15200493(1976)104<1429:VSOTO>2.0.CO;2.

Gunter, W. S., and J. L. Schroeder, 2015: High-resolution full-scale measurements of thunderstorm outflow winds. J. Wind Eng. Ind. Aerodyn., 138, 13-26, https://doi.org/10.1016/j.jweia.2014.12.005.

,-- C. C. Weiss, and E. C. Bruning, 2017: Surface measurements of the 5 June 2013 damaging thunderstorm wind event near Pep, Texas. Wind Struct., 24, 185-204, https:// doi.org/10.12989/was.2017.24.2.185.

Hjelmfelt, M. R., 1988: Structure and life cycle of microburst outflows observed in Colorado. J. Appl. Meteor., 27, 900-927, https:// doi.org/10.1175/1520-0450(1988)027<0900:SALCOM>2.0.CO;2.

Holmes, J. D., H. M. Hangan, J. L. Schroeder, C. W. Letchford, and K. D. Orwig, 2008: A forensic study of the Lubbock-Reese downdraft of 2002. Wind Struct., 11, 137-152, https://doi.org/ 10.12989/was.2008.11.2.137.

Horvath, L., 1993: The maximum likelihood method for testing changes in the parameters of normal observations. Ann. Stat., 21, 671-680, https://doi.org/10.1214/aos/1176349143.

Hu, W., F. Letson, R. J. Barthelmie, and S. C. Pryor, 2018: Wind gust characterization at wind turbine relevant heights in moderately complex terrain. J. Appl. Meteor. Climatol., 57, 1459-1476, https://doi.org/10.1175/JAMC-D-18-0040.1.

Jackson, B., and Coauthors, 2005: An algorithm for optimal partitioning of data on an interval. IEEE Signal Process. Lett., 12 , 105-108, https://doi.org/10.1109/LSP.2001.838216.

Jackson, L. B., 1996: Digital Filters and Signal Processing. Springer Science \& Business Media, 502 pp. 
Järvi, L., and Coauthors, 2007: Micrometeorological observations of a microburst in southern Finland. Bound.-Layer Meteor., 125, 343-359, https://doi.org/10.1007/s10546-007-9204-7.

Jubayer, C., D. Romanic, and H. Hangan, 2019: Aerodynamic loading of a typical low-rise building for an experimental stationary and non-Gaussian impinging jet. Wind Struct., 28, 315-329, https://doi.org/10.12989/was.2019.28.5.315.

Junayed, C., C. Jubayer, D. Parvu, D. Romanic, and H. Hangan, 2019: Flow field dynamics of large-scale experimentally produced downburst flows. J. Wind Eng. Ind. Aerodyn., 188, 6179, https://doi.org/10.1016/j.jweia.2019.02.008.

Kendall, M. G., A. Stuart, and J. K. Ord, 1983: The Advanced Theory of Statistics. 4th ed. Macmillan Publishing Co. Inc., 585 pp.

Killick, R., P. Fearnhead, and I. A. Eckley, 2012: Optimal detection of changepoints with a linear computational cost. J. Amer. Stat. Assoc., 107, 1590-1598, https://doi.org/10.1080/01621459.2012.737745.

Lareau, N. P., E. Crosman, C. D. Whiteman, J. D. Horel, S. W. Hoch, W. O. J. Brown, and T. W. Horst, 2013: The persistent cold-air pool study. Bull. Amer. Meteor. Soc., 94, 51-63, https://doi.org/10.1175/BAMS-D-11-00255.1.

Lavielle, M., 1999: Detection of multiple changes in a sequence of dependent variables. Stochastic Process. Appl., 83, 79-102, https://doi.org/10.1016/S0304-4149(99)00023-X.

_ 2005: Using penalized contrasts for the change-point problem. Signal Process., 85, 1501-1510, https://doi.org/10.1016/ j.sigpro.2005.01.012.

Lemon, L. R., and C. A. Doswell, 1979: Severe thunderstorm evolution and mesocyclone structure as related to tornadogenesis. Mon. Wea. Rev., 107, 1184-1197, https://doi.org/ 10.1175/1520-0493(1979)107<1184:STEAMS >2.0.CO;2.

Lombardo, F. T., 2009: Analysis and interpretation of thunderstorm wind flow on a bluff body. Ph.D. dissertation, Texas Tech University, $259 \mathrm{pp}$.

_ , and A. S. Zickar, 2019: Characteristics of measured extreme thunderstorm near-surface wind gusts in the United States. J. Wind Eng. Ind. Aerodyn., 193, 103961, https://doi.org/ 10.1016/j.jweia.2019.103961.

_ J. A. Main, and E. Simiu, 2009: Automated extraction and classification of thunderstorm and non-thunderstorm wind data for extreme-value analysis. J. Wind Eng. Ind. Aerodyn., 97, 120-131, https://doi.org/10.1016/j.jweia.2009.03.001.

- D. A. Smith, J. L. Schroeder, and K. C. Mehta, 2014: Thunderstorm characteristics of importance to wind engineering. J. Wind Eng. Ind. Aerodyn., 125, 121-132, https:// doi.org/10.1016/j.jweia.2013.12.004.

Lompar, M., M. Ćurić, and D. Romanic, 2017: Simulation of a severe convective storm using a numerical model with explicitly incorporated aerosols. Atmos. Res., 194, 164-177, https:// doi.org/10.1016/j.atmosres.2017.04.037.

,-- , and,- 2018 : Implementation of a gust front head collapse scheme in the WRF numerical model. Atmos. Res., 203, 231-245, https://doi.org/10.1016/j.atmosres.2017.12.018.

Markowski, P. M., 2002: Hook echoes and rear-flank downdrafts: A review. Mon. Wea. Rev., 130, 852-876, https://doi.org/10.1175/ 1520-0493(2002)130<0852:HEARFD > 2.0.CO;2.

_- and Y. Richardson, 2010: Mesoscale Meteorology in MidLatitudes. John Wiley \& Sons, Ltd., 430 pp.

Mueller, C. K., and R. E. Carbone, 1987: Dynamics of a thunderstorm outflow. J. Atmos. Sci., 44, 1879-1898, https://doi.org/ 10.1175/1520-0469(1987)044<1879:DOATO > 2.0.CO;2.

NCEI, 1998: Automated Surface Observing System (ASOS). NOAA/ National Centers for Environmental Information (NCEI) formerly known as National Climatic Data Center (NCDC), accessed 2 February 2020, https://www.ncdc.noaa.gov/dataaccess/land-based-station-data/land-based-datasets/automatedsurface-observing-system-asos.

Neter, J., M. Kutner, W. Wasserman, and C. Nachtsheim, 1996: Applied Linear Statistical Models. 4th ed. McGraw-Hill/Irwin, 1408 pp.

Orwig, K. D., and J. L. Schroeder, 2007: Near-surface wind characteristics of extreme thunderstorm outflows. J. Wind Eng. Ind. Aerodyn., 95, 565-584, https://doi.org/10.1016/j.jweia.2006.12.002.

Pan, Y., and E. G. Patton, 2017: On determining stationary periods within time series. J. Atmos. Oceanic Technol., 34, 2213-2232, https://doi.org/10.1175/JTECH-D-17-0038.1.

Parks, T. W., and C. S. Burrus, 1987: Digital Filter Design. John Wiley \& Sons, 368 pp.

Repetto, M. P., M. Burlando, G. Solari, P. De Gaetano, M. Pizzo, and M. Tizzi, 2018: A web-based GIS platform for the safe management and risk assessment of complex structural and infrastructural systems exposed to wind. Adv. Eng. Software, 117, 29-45, https://doi.org/10.1016/j.advengsoft.2017.03.002.

Rohatgi, A., 2019: WebPlotDigitalizer: HTML5 based online tool to extract numerical data from plot images, version 4.2. Accessed 6 July 2019, https://apps.automeris.io/wpd/.

Romanic, D., D. Parvu, M. Refan, and H. Hangan, 2018: Wind and tornado climatologies and wind resource modelling for a modern development situated in "Tornado Alley." Renewable Energy, 115, 97-112, https://doi.org/10.1016/j.renene.2017.08.026.

_, J. LoTufo, and H. Hangan, 2019: Transient behavior in impinging jets in crossflow with application to downburst flows. J. Wind Eng. Ind. Aerodyn., 184, 209-227, https://doi.org/ 10.1016/j.jweia.2018.11.020.

Schroeder, J. L., and D. A. Smith, 2003: Hurricane Bonnie wind flow characteristics as determined from WEMITE. J. Wind Eng. Ind. Aerodyn., 91, 767-789, https://doi.org/10.1016/S0167-6105(02)00475-0.

Shabbott, C. J., and P. M. Markowski, 2006: Surface in situ observations within the outflow of forward-flank downdrafts of supercell thunderstorms. Mon. Wea. Rev., 134, 1422-1441, https://doi.org/10.1175/MWR3131.1.

Sherman, D. J., 1987: The passage of a weak thunderstorm downburst over an instrumented tower. Mon. Wea. Rev., 115, 1193-1205, https:// doi.org/10.1175/1520-0493(1987)115<1193:TPOAWT>2.0.CO;2.

Solari, G., 1983: Analytical estimation of the alongwind response of structures. J. Wind Eng. Ind. Aerodyn., 14, 467-477, https:// doi.org/10.1016/0167-6105(83)90047-8.

_ 2016: Thunderstorm response spectrum technique: Theory and applications. Eng. Struct., 108, 28-46, https://doi.org/ 10.1016/j.engstruct.2015.11.012.

- M. P. Repetto, M. Burlando, P. De Gaetano, M. Pizzo, M. Tizzi, and M. Parodi, 2012: The wind forecast for safety management of port areas. J. Wind Eng. Ind. Aerodyn., 104106, 266-277, https://doi.org/10.1016/j.jweia.2012.03.029.

M. Burlando, P. De Gaetano, and M. P. Repetto, 2015: Characteristics of thunderstorms relevant to the wind loading of structures. Wind Struct., 20, 763-791, https://doi.org/10.12989/ was.2015.20.6.763.

Wakimoto, R. M., 1982: The life cycle of thunderstorm gust fronts as viewed with Doppler radar and rawinsonde data. Mon. Wea. Rev., 110, 1060-1082, https://doi.org/10.1175/1520-0493(1982)110<1060: TLCOTG $>2.0 . \mathrm{CO} ; 2$.

Welch, P., 1967: The use of fast Fourier transform for the estimation of power spectra: A method based on time averaging over short, modified periodograms. IEEE Trans. Audio Electroacoust., 15, 70-73, https://doi.org/10.1109/TAU.1967.1161901. 